Pontifícia Universidade Católica $_{\text {mand }}$

Rodrigo Huber Marques Moreira Mendes

Avaliação metrológica de modelos de previsão a curto prazo da irradiação solar na superfície

terrestre

Dissertação de Mestrado

Dissertação apresentada como requisito parcial para obtenção do grau de Mestre pelo Programa de Pós-graduação em Metrologia (Área de concentração: Metrologia para Qualidade e Inovação) da PUC-Rio.

Orientador: Prof. Alcir de Faro Orlando

Rio de Janeiro

Dezembro de 2020 


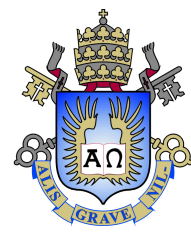

Rodrigo Huber Marques Moreira Mendes

\section{Avaliação metrológica de modelos de previsão a curto prazo da irradiação solar na superfície terrestre}

Dissertação apresentada como requisito parcial para obtenção do grau de Mestre pelo Programa de Pós-graduação em Metrologia (Área de concentração: Metrologia para Qualidade e Inovação) da PUC-Rio. Aprovada pela Comissão Examinadora abaixo:

Prof. Alcir de Faro Orlando

Orientador

Programa de Pós-Graduação em Metrologia - PUC-Rio

Prof. Sergio Leal Braga

Departamento de Engenharia Mecânica - PUC-Rio

Dra. lakyra Borrakuens Couceiro Divisão de Metrologia Óptica - INMETRO

Prof. José Daniel Hernández Vásquez

Universidad Antonio Nariño

Rio de Janeiro, 18 de Dezembro de 2020 
Todos os direitos reservados. A reprodução, total ou parcial do trabalho, é proibida sem a autorização da universidade, do autor e do orientador.

\section{Rodrigo Huber Marques Moreira Mendes}

Graduado em Engenharia Mecânica pela Pontifícia Universidade Católica do Rio de Janeiro, possui ampla experiência na área de energias alternativas, sustentabilidade e desenvolvimento estratégico. Fez parte da equipe que implementou e validou o sistema de utilização de energia solar para preaquecimento dos motores da central termelétrica Gera Maranhão.

Ficha Catalográfica

Huber Marques Moreira Mendes, Rodrigo

Avaliação metrológica de modelos de previsão a curto prazo da irradiação solar na superfície terrestre / Rodrigo Huber Marques Moreira Mendes; orientador: Alcir de Faro Orlando. -2020.

65 f: il. color. ; $30 \mathrm{~cm}$

Dissertação (mestrado) - Pontifícia Universidade Católica do Rio de Janeiro, Centro Técnico Científico, Programa de Pós-Graduação em Metrologia, 2020.

Inclui bibliografia

1. Metrologia - Teses. 2. Metrologia para Qualidade e Inovação - Teses. 3. Energia Solar. 4. Metrologia. 5. Previsão. 6. Transmitância Atmosférica. I. de Faro Orlando, Alcir. II. Pontifícia Universidade Católica do Rio de Janeiro. Centro Técnico Científico, Programa de Pós-Graduação em Metrologia III. Título. 


\section{Agradecimentos}

Em primeiro lugar à mim mesmo, por acreditar e persistir nesta incrível jornada.

À minha família.

Ao meu orientador.

Ao amigo Matheus Donadio, que diversas vezes ajudou nas rotinas de programação em Python, sem o qual seria impossível realizar este trabalho.

À todos que diretamente ou indiretamente ajudaram para a conclusão desta dissertação.

À CAPES e à PUC-Rio, pelos auxílios concedidos, sem os quais este trabalho não poderia ter sido realizado

O presente trabalho foi realizado com apoio da Coordenação de Aperfeiçoamento de Pessoal de Nível Superior - Brasil (CAPES) - Código de Financiamento 001 . 


\section{Resumo}

Huber Marques Moreira Mendes, Rodrigo; de Faro Orlando, Alcir. Avaliação metrológica de modelos de previsão a curto prazo da irradiação solar na superfície terrestre. Rio de Janeiro, 2020. 65p. Dissertação de Mestrado - Pontifícia Universidade Católica do Rio de Janeiro, Programa de Pós-Graduação em Metrologia.

A previsão da energia elétrica produzida com energia solar pode ser usada para monitorar em tempo real seu desempenho, permitindo a identificação de problemas operacionais ou sua degradação, assim como a previsão da produção de energia elétrica a curto e médio prazo, permitindo otimizar o uso da rede. Normalmente, a previsão de dados climáticos ao longo do dia serve para ajudar a estabilidade da rede elétrica. Já a previsão de dados para um dia ou mais à frente serve para apoiar a participação de mercado. Esta pesquisa tem como objetivo geral propor um modelo de previsão a curto prazo da irradiação solar a partir de correlações de condições climáticas, visando diminuir as incertezas de previsão da mesma, que pode ser usado para prever a geração fotovoltaica. O modelo de previsão proposto se baseia em identificar os dias de céu limpo, caracterizados pela ausência de nuvens, e dias totalmente nublados. Para sua identificação, foram utilizadas formulações já consagradas na literatura. Para os demais dias, a previsão da irradiação é feita a partir de regressões e correlações entre temperatura ambiente e transmitância atmosférica. A escolha do modelo de céu limpo é um fator preponderante para a previsão, podendo aumentar significativamente sua confiabilidade. Diversos modelos de previsão foram avaliados e combinados para uma melhor previsão da irradiação solar média incidente na superfície terrestre. A partir de dados de irradiação solar e temperatura, medidos a cada minuto por quatro anos na cidade de Miranda do Norte, Maranhão, foi possível analisar, interpretar e propor um modelo para a previsão da irradiação solar média com incertezas de $22-24 \%, 14-16 \%, 13-15 \%$ e 12-13\%, a nível de confiabilidade de 95,45\%, respectivamente para horizontes de $1,3,5$ e 7 dias à frente. A utilização do método dos mínimos quadrados para previsão apresenta incertezas muito maiores. O modelo proposto apresenta-se eficaz para prever a irradiação solar. Sua utilização e facilidade de implementação podem ser de grande valia para a prever o planejamento diário e semanal da produção de usinas fotovoltaicas. Foi usado o modelo de previsão sugerido por Bindi, juntamente com três modelos de céu limpo para redução da incerteza de previsão.

\section{Palavras-chave}

Energia Solar; Metrologia; Previsão; Transmitância Atmosférica. 


\section{Abstract}

Huber Marques Moreira Mendes, Rodrigo; de Faro Orlando, Alcir (Advisor). Metrological evaluation of short term solar irradiation forecast models on the earth surface. Rio de Janeiro, 2020. 65p. Dissertação de Mestrado - Pontifícia Universidade Católica do Rio de Janeiro, Programa de Pós-Graduação em Metrologia.

The prediction of the electric energy production by solar energy systems can be used as a real time monitoring of its performance, allowing the identification of operational problems or its performance degradation, as well as the short and medium term production of electric energy, thus optimizing the use of the electric network. Normally, the daylong climactic data prediction is useful for helping stabilizing the electric network. The one or more day ahead prediction of electric energy is a useful tool for planning the energy supply to the market. The main goal of this research is to propose a short-term prediction model for the solar irradiation by means of weather condition correlations, in doing so, we expect to lower the uncertainties of the solar irradiation forecast, for which can be used to forecast photovoltaic energy. The proposed prediction model uses literature available correlations for clear sky (no clouds) and overcast days, to predict the solar irradiation in other days, through the use the ambient temperature and atmospheric transmission literature available correlations. Several prediction models were used and combined for 1, 3, 5 and 7 days ahead prediction of the available average solar energy in that time interval. It was concluded that the clear sky model plays an important role in the prediction reliability. Experimental data taken every minute for almost four years in the city of Miranda do Norte in the state of Maranhão, Brazil, were used to verify and propose a model to better predict the available solar energy irradiation, to within 22-24 \%, 14-16\%,13-15\% and 12-13\% uncertainty $(95,45 \%$ confidence level), respectively for $1,3,5$ and 7 days ahead of the available solar irradiation in the time interval. The least square model was also analyzed and it was shown to predict the solar irradiation with much higher uncertainties. As a result, the proposed model can be easily implemented for predictions in other places and can be very useful for predicting and planning the daily and weekly output of photovoltaic plants. In this dissertation the prediction model suggested by Bindi was utilized, together with three clear sky models to reduce the prediction uncertainty.

\section{Keywords}

Solar Energy; Atmosferic Transmittance; Metrology; Forecast. 


\section{Sumário}

1 Introdução $\quad 13$

1.1 Contextualização 13

$\begin{array}{lll}1.2 & \text { Motivação } & 19\end{array}$

1.3 Objetivos: geral e específicos 20

1.4 Estrutura da dissertação 21

2 Fundamentos Teóricos $\quad 22$

2.1 Radiação extraterrestre em uma superfície horizontal 22

$\begin{array}{lll}2.2 & \text { A variação da radiação extraterrestre anual } & 23\end{array}$

2.3 Definições 23

2.4 Cálculo da Hora Solar 24

2.5 Direção da Radiação Direta 24

2.6 Radiação extraterrestre em uma superfície horizontal 25

2.7 Atenuação Atmosférica da Radiação Solar 26

2.8 Estimativa da média diária de radiação solar incidente 26

2.9 Radiação de céu limpo 26

3 Metodologia e Modelos de Previsão 28

3.1 Análise do erro e incertezas 28

$\begin{array}{lll}3.1 .1 & \text { RMSE } & 28\end{array}$

$\begin{array}{lll}3.1 .2 & \text { Incerteza de Previsão } & 29\end{array}$

$\begin{array}{lll}3.2 & \text { Modelos mais utilizados } & 30\end{array}$

3.2.1 Escolha do melhor método 31

$\begin{array}{lll}3.3 & \text { Previsão da transmitância atmosférica } & 31\end{array}$

3.3.1 O fenômeno físico 31

3.3.2 Identificação de dias de Céu Limpo e dias Totalmente Nublados (Overcast)) 32

3.3.3 Previsão da transmitância média para dias Intermediários 33

4 Céu Limpo $\quad 34$

4.1 Definição, aplicabilidade e classificação dos modelos 34

4.2 Escolha do modelo mais adequado 35

4.3 Formulação dos modelos de Céu Limpo 36

4.4 Dias Totalmente Nublados (Overcast) 38

5 Modelagem $\quad 39$

$\begin{array}{lll}5.1 & \text { Obtenção de dados } & 39\end{array}$

5.2 Cálculos primários 40

5.3 Cálculo da Transmitância Real (analítica) 40

5.4 Cálculo da Transmitância de Céu Limpo 41

5.5 Cálculo da Transmitância de Céu Totalmente Nublado (Overcast) 41

5.6 Previsão da radiação no nível do solo 42

5.6.1 Modelos utilizados 42 
6 Resultados $\quad 43$

6.1 Previsão em função do modelo de céu limpo escolhido 43

6.1.1 Análise dos erros de previsão 43

6.1.2 Análise gráfica dos modelos de céu limpo 45

6.2 Modelo Proposto 48

6.3 Mínimos quadrados ordinários $(O L S) \quad 51$

7 Conclusões e Recomendações para Trabalhos Futuros $\quad 54$

7.1 Conclusões 54

7.2 Recomendações para Trabalhos Futuros 55

$\begin{array}{ll}\text { Referências bibliográficas } & 56\end{array}$

$\begin{array}{lll}\text { A Apêndice } & 61\end{array}$

A.I Atlas solar da cidade de Miranda do Norte 61 


\section{Lista de figuras}

Figura 6.1 Gráfico comparativo entre as formulações para transmitâncias de céu limpo e a transmitãncia medida, para o ano de 2017

Figura 6.2 Gráfico comparativo entre as formulações para transmitâncias de céu limpo e a transmitãncia medida, para o ano de 2018

Figura 6.3 Gráfico comparativo entre as formulações para transmitâncias de céu limpo e a transmitãncia medida, para o ano de 2019

Figura 6.4 Gráfico comparativo entre as formulações para transmitâncias de céu limpo e a transmitãncia medida, para o ano de 2020 


\section{Lista de tabelas}

Tabela 6.1 Comparativo de erros de previsão - Ano $2017 \quad 44$

Tabela 6.2 Comparativo de erros de previsão - Ano 2018

Tabela 6.3 Comparativo de erros de previsão - Ano 201944

Tabela 6.4 Comparativo de erros de previsão - Ano $2020 \quad 44$

$\begin{array}{lll}\text { Tabela 6.5 } & \text { RMSE para o Ano } 2017 & 49\end{array}$

Tabela 6.6 RMSE para o Ano 2018

Tabela 6.7 RMSE para o Ano 2019

Tabela 6.8 RMSE para o Ano $2020 \quad 50$

Tabela 6.9 RMSE para o Ano 2017

Tabela 6.10 RMSE para o Ano $2018 \quad 52$

Tabela 6.11 RMSE para o Ano 2019

Tabela 6.12 RMSE para o Ano 2020

$\begin{array}{lll}\text { Tabela A.1 Atlas Solar - Ano } 2017 & 62\end{array}$

Tabela A.2 Atlas Solar - Ano 2018

Tabela A.3 Atlas Solar - Ano 2019

Tabela A.4 Atlas Solar - Ano $2020 \quad 65$ 


\section{Lista de Abreviaturas}

RMSE - Raiz do erro médio quadrático (root mean square error)

GFS - Global Forecast System

GEM - Global Environment Multiscale Model

IGCM - Intermediate General Circulation Model

UM - Unified Model

GME - German Weather Service

WRF - Weather Research and Forecasting

ALADIN - Aire Limitée Adaptation Dynamic

ARPS - Advanced Regional Prediction System

MM5 - Fifth Generation Penn State/NCAR

GEM-LAM - Global Environmental Multiscale Limites Area Model

INPE - Instituto Nacional de Pesquisas Espaciais

INMET - Instituto Nacional de Meteorologia

INMETRO - Instituto Nacional de Metrologia, Qualidade e Tecnologia

MLP - Multilayer perceptron

NREL - National Renewable Energy Laboratory 
A human being should be able to change a diaper, plan an invasion, butcher a hog, conn a ship, design a building, write a sonnet, balance accounts, build a wall, set a bone, comfort the dying, take orders, give orders, cooperate, act alone, solve equations, analyse a new problem, pitch manure, program a computer, cook a tasty meal, fight efficiently, die gallantly. Specialization is for insects.

Robert A. Heinlein, Time Enough for Love. 


\section{Introdução}

A alteração do paradigma energético surgiu com o aparecimento de pequenos produtores energéticos, usando uma produção baseada em fontes de energia renováveis, como solar fotovoltaico e eólica[1]. Este fato obrigou a alteração da arquitetura tradicional das redes de energia elétrica, de centralizada para descentralizada, exigindo, para sua gestão, tecnologias de informação e comunicação mais avançadas, assim como uma integração entre os consumidores como participantes ativos. As chamadas redes inteligentes (smart grids) são capazes de coordenar as necessidades e as capacidades de todos os produtores e operadores da rede, de forma tão eficiente quanto possível, minimizando custos e impactos ambientais e, ao mesmo tempo, maximizando a confiabilidade do sistema[1].

Um problema atualmente existente nas redes inteligentes está relacionado com os agentes produtores, que precisam atender às necessidades energéticas dos clientes finais, normalmente estimando sua produção com base nas características dos equipamentos instalados e em parâmetros meteorológicos, como irradiação solar, temperatura ambiente, pluviosidade e velocidade do vento[1]. Muitas vezes o responsável pela gestão das redes de energia não tem capacidade de estimar o que será produzido pelos pequenos e grandes produtores de energias renováveis, deixando a diferença em relação às necessidades do cliente final ser suprida por outras formas de energia. A previsão da quantidade de energia não é simples e linear, requerendo a utilização de métodos de análise de dados e aplicação de modelos desenvolvidos especificamente para cada caso[1].

\section{1}

\section{Contextualização}

A previsão da energia produzida permite a monitoração em tempo real dos sistemas de produção, permitindo a detecção de avarias ou a sua degradação, assim como a previsão da produção de energia elétrica a curto e médio prazo, permitindo balancear mais eficientemente o fluxo de energia através da rede. Normalmente, a previsão de dados climáticos ao longo do dia serve para subsidiar a estabilidade da rede elétrica. Já a previsão de dados para um dia ou mais à frente serve para apoiar a participação de mercado[2]. 
Diferentes tipos de dados são utilizados para gerar previsões da energia produzida, desde medições meteorológicas e de produção de sistemas fotovoltaicos, até a observação de nuvens por satélite e imagens do céu, e modelos de simulação numéricos da atmosfera[2]. A escolha do modelo depende do horizonte de previsão considerado. Previsões a muito curto prazo (0 a 6 horas à frente) fornecem melhores resultados com dados medidos, ao passo que modelos de simulação numérica da atmosfera se tornam fundamentais para horizontes além de 6 horas [2]. Melhores resultados são conseguidos usando dados medidos para pós-processar os modelos de simulação numérica da atmosfera, corrigindo erros sistemáticos [2]. Comparações entre previsões são importantes para determinar a sua confiabilidade, uma vez que a exatidão depende de muitos fatores, como clima local, horizonte, previsão do tempo, e se os resultados são aplicados a um único ponto ou cobrem uma área geográfica extensa, o que é de maior interesse para os operadores do sistema elétrico.

Previsões com dados de satélite (4 horas à frente) e simulação numérica da atmosfera (1 dia à frente) são as melhores ferramentas de previsão[3].

Os modelos de simulação numérica de macro escala da atmosfera são os que oferecem previsões meteorológicas de maior alcance. Utilizam para sua parametrização[4] modelos para várias regiões da atmosfera, tais como: (a) Camada limite superficial; (b) Camada limite atmosférica; (c) Superfície do solo; (d) Microfísica; (e) Radiação de onda longa; (f) Radiação de ondas curtas; e (g) Cúmulos. Como dados de entrada, utilizam a radiação solar incidente do topo da atmosfera, conhecida com muita exatidão como função da posição relativa do sol ao longo do dia além de modelos de parametrização para várias regiões da atmosfera, e como dados de saída fornecem valores de previsão dos parâmetros meteorológicos, como temperatura, umidade relativa, cobertura de nuvens e irradiação solar.

Os modelos classificados como Globais[5] têm como objetivo identificar o comportamento geral da atmosfera em larga escala em um horizonte de até 7 dias. Os principais modelos globais[5] desenvolvidos são, (a) GFS - Global Forecast System; (b) GEM - Global Environment Multiscale Model; (c) IGCM - Intermediate General Circulation Model; (d) UM - Unified Model e (e) GME - German Weather Service.

Os modelos classificados como Regionais/Locais[5] são de extrema importância para a previsão da energia solar fotovoltaica, uma vez que permitem estudar uma determinada zona geográfica com grande resolução espacial, como por exemplo, o estudo de um parque solar fotovoltaico. O modelo WRF (Weather Research and Forecasting) foi desenvolvido por um conjunto de entidades operacionais e de pesquisa nos Estados Unidos, sendo atualmente uma refe- 
rência em termos de modelagem numérica em muitos países. Podem fornecer previsões para um horizonte de 3 a 72 horas. Outros modelos disponíveis são [5], (a) ALADIN - Aire Limitée Adaptation Dynamic, (b) ARPS - Advanced Regional Prediction System, (c) MM5 - Fifth Generation Penn State / NCAR, (d) GEM-LAM - Global Environmental Multiscale Limites Area Model.

A previsão da produção de energia elétrica por uma planta fotovoltaica também pode ser verificada pela comparação direta entre a energia produzida por ela e os dados previstos pelos modelos numéricos ou dados medidos de irradiação solar e temperatura ambiente. A vantagem desta metodologia é a determinação de uma possível deriva de desempenho da planta fotovoltaica ao longo de um determinado período de tempo[6], tornando mais confiável a previsão. Ela requer, entretanto, que estejam disponíveis dados de desempenho de uma planta ao longo de um determinado período de tempo, o que nem sempre é possível. A confiabilidade da previsão da energia elétrica produzida, neste caso, é fundamentalmente dependente dos modelos de simulação numérica e do seu horizonte temporal.

No Brasil, O Instituto Nacional de Pesquisas Espaciais (INPE) fornece dados de previsão do comportamento da atmosfera. Existem também outras instituições que prestam o mesmo serviço, disponível ao público em geral.

Estes modelos de simulação numérica da atmosfera apresentam, assim, uma previsão da irradiação solar e da temperatura ambiente em vários horizontes temporais, que podem ser usados como dados de entrada para a previsão de produção da energia elétrica por uma planta fotovoltaica, com características de desempenho determinadas em testes realizados pelos laboratórios acreditados pelo Programa Brasileiro de Etiquetagem, administrado pelo INMETRO[7].

Estes modelos numéricos podem ser verificados pela comparação entre os dados previstos e os dados medidos ao longo de um determinado período de tempo. Dados horários obtidos por estações automáticas administradas pelo Instituto Nacional de Meteorologia (INMET) estão disponíveis para muitas cidades do Brasil. Para o desenvolvimento desta dissertação foram utilizados dados obtidos a cada minuto durante 44 meses na cidade de Miranda do Norte, no Maranhão[8], obtidos com uma estação meteorológica especificada, adquirida e instalada no contexto do projeto de P\&D da ANEEL PD-64920113/2013. Nesta dissertação foi elaborado um Atlas de irradiação solar mensal média,apresentado no Apêndice A, a partir dos dados monitorados na cidade de Miranda do Norte durante esta pesquisa.

Da comparação direta entre a energia produzida e os dados previstos, podem resultar fatores de correção a serem aplicados aos resultados dos 
modelos, representados por uma curva de ajuste, aumentando a confiabilidade da previsão. Uma curva de ajuste deve ser escolhida com base no número de pontos disponíveis e na tendência evidenciada pelo processo físico, para esta análise, é utilizado o último período com duração a ser escolhida pelos resultados alcançados. Normalmente uma combinação entre o valor do RMSE ${ }^{1}$ e a representação do fenômeno físico pela curva é o critério de escolha.

Definindo-se o erro de previsão como a diferença entre o valor da previsão realizada e um valor de referência(valor medido em campo), um critério que pode ser utilizado para determinação dos parâmetros desta curva é a minimização do erro médio quadrático. Ele apresenta a vantagem de estatisticamente determinar uma curva o mais equidistante possível entre os pontos da comparação e, portanto, representar a curva mais provável. Este espalhamento, juntamente com a influência da medição das variáveis meteorológicas, é levado em consideração na estimativa da incerteza de previsão dos parâmetros da atmosfera $[9]$.

Tem sido observado [10] que, se uma série temporal apresentar multialeatoriedade em seus padrões, um número maior de observações pode ser necessário. Ela fica mais imune a ruídos e movimentos bruscos.

Polinômios de vários graus têm sido muito utilizados como função de ajuste[11]. A minimização do desvio médio quadrático resulta em um sistema de equações lineares a ser resolvido. Muitas vezes, entretanto, funções não lineares são usadas por se ajustarem melhor aos dados. Neste caso, a minimização do desvio médio quadrático deve ser feita iterativamente por meio de algoritmos como o de Levenberg-Marquardt[11], que combina as melhores características do método da busca pelo gradiente com o método de linearização da função de ajuste.

Muitas vezes, o intervalo total é subdividido em vários trechos, nos quais polinômios do terceiro grau (spline fitting), por exemplo, são utilizados para ajustar os pontos em cada um deles. Para haver continuidade, as condições de compatibilidade nas junções entre os mesmos exigem que os valores da função, primeira derivada e segunda derivada sejam os mesmos para dois polinômios vizinhos. A minimização do desvio médio quadrático pode ser feita usando-se o método dos multiplicadores de Lagrange, o que resulta em um sistema de equações lineares a ser resolvido[12]. Como o número de equações pode crescer muito com o número de intervalos, deve-se avaliar se é mais interessante usar funções não lineares.

Um outro método que tem sido usado ultimamente para previsão da irradiação solar são as Redes Neurais Artificiais[13]. É um método iterativo

\footnotetext{
${ }^{1}$ RMSE - Raiz do erro médio quadrático (root mean square error)
} 
que suporta não linearidades na função de ajuste. Para minimização do desvio médio quadrático entre os valores previstos e medidos, as variáveis de entrada são combinadas por funções peso com valores determinados pelo algoritmo de Levenberg-Marquardt, utilizando a função sigmóide logística com função de ativação nas camadas internas e de saída. Existem outros algoritmos como (a) Resilient Backpropagation, (b) Gradiente conjugado escalar, (c) Taxa de aprendizagem variável e, (d) Taxa de aprendizagem variável com momento. Muito embora o algoritmo de Levenberg-Marquardt precise de um maior tempo para convergência, foi mostrado por [13] que seu uso resulta em menores desvios médios quadráticos. Também foi concluído pelo mesmo trabalho que é possível utilizar redes do tipo MLP (Multilayer perceptron) com sucesso para modelagem de parâmetros instantâneos de radiação solar a partir apenas de informações sobre a cobertura de nuvens. O seu emprego na modelagem da integral diária da radiação solar empregando um conjunto de variáveis climatológicas deve ser melhor estudado.

Redes neurais com diferentes configurações têm sido utilizadas com o intuito de redução do desvio médio quadrático[13].

No Brasil, foi utilizado com sucesso um modelo de mesoescala WRF ajustado por redes neurais artificiais[6], comparando-se os valores previstos com os medidos em 121 estações automáticas do Nordeste, durante cerca de 7 anos. Após a previsão dos dados foi realizada a extração dos dados pelos softwares MATLAB e SURFER. Foram usadas redes neurais para pósprocessar os dados, comparando os dados previstos com os dados medidos de irradiação solar. Também foi empregado o método de regressões lineares múltiplas, que se mostrou inferior às redes neurais. O modelo calcula a fração de cobertura de nuvens. Foi utilizado um modelo de céu limpo e então calculado o índice de clareza, definido com a relação entre a irradiação global medida e a de céu claro. O modelo de Hottel[14] tem sido usado e tem como dados de entrada o ângulo de Azimute e a altitude do observador, além de fatores de correção para tipos de clima. A irradiação solar foi calculada por regressão linear múltipla como função da cobertura de nuvens.

Métodos estatísticos foram utilizados em [10] para fazer a previsão de irradiação solar. Foram utilizados o método de médias móveis e de projeção exponencial. Este último se tornou mais eficaz e se assemelha muito com as redes neurais, porém sem a metodologia para determinação da constante de suavização.

Utilizando um modelo atmosférico de mesoescala regional RAMS[15] foi verificada uma forte correlação entre a fração de cobertura de nuvens e a razão entre a irradiação solar observada na superfície e no topo da atmosfera, 
chegando-se a uma correlação para a irradiação solar.

Uma análise de diferentes ferramentas para previsão foi feita por [1], usando o software WEKA, desenvolvido pela Universidade de Waikato (Nova Zelândia) e disponível gratuitamente pela Internet.

A literatura mostra que muitos trabalhos têm sido publicados sobre a previsão de geração de energia elétrica, via solar e eólica, com um dia à frente. Uma comparação de estratégias para obter previsões regionais com um dia na frente é feita em [16]. Um trabalho para previsão da geração de energia elétrica com energia solar no Sudoeste Americano[17] mostrou que as previsões podem ser melhoradas pela remoção dos erros sistemáticos empregando uma regressão polinomial que utiliza o ângulo de zênite e o índice de clareza. Desta forma, a previsão da irradiação solar pode ser feita como um pós-processamento dos resultados da simulação numérica da atmosfera, corrigindo os resultados obtidos e melhorando a precisão dos valores através do desenvolvimento de correlações, utilizando os dados meteorológicos mencionados anteriormente de Miranda do Norte e de estações do INMET.

O primeiro passo neste desenvolvimento é a escolha das variáveis independentes para uma expressão para o cálculo da irradiação solar.

A correlação de Bennett foi validada em [18] para as médias mensais da razão entre a radiação solar incidente numa superfície horizontal e a correspondente extraterrestre. Ela é função da relação entre o número de horas de insolação, que exclui os períodos de sua ausência, e a duração astronômica do dia, além da altitude do lugar. Outra correlação foi desenvolvida [19] relacionando a transmitância atmosférica com a diferença entre a maior e a menor temperatura do dia, que apesar de ter obtido um coeficiente de correlação alto entre a transmitância atmosférica e as temperaturas máximas e mínimas diárias ( $\mathrm{r}=0,95$ ), esta correlação só pode ser comparável para localidades típicamente similares às estudadas pelo autor (Pullman, Seattle, Tacoma ou Great Falls nos Estados Unidos da América), para as demais localidades a serem implementadas deve ser feito um ajuste de suas constantes. Da mesma forma, uma correlação foi desenvolvida [20] para cálculo da irradiação solar como função da umidade relativa e do número de horas de insolação, onde obteve-se uma formulação simples mas que necessita também de ajustes para ser implementada e esta correlação por sua vez, pode não representar corretamente 10-30\% de todas as condições atmosféricas.

Para o desenvolvimento destas correlações é necessário que esteja disponível um número grande de dados meteorológicos em diferentes localidades e condições climáticas, nem sempre disponíveis. Para contornar esta dificuldade, tem sido estudado um tipo de modelo de previsão da irradiação solar que utiliza 
correlações desenvolvidas para dois casos extremos, obtidos com um número grande de dados meteorológicos, (a) Céu limpo, com ausência de nuvens, e, (b) Céu completamente nublado. As condições intermediárias são obtidas através de correlações simples que têm sido desenvolvidas, o modelo de Bindi[21], que desenvolveu um procedimento de extrapolação para a previsão da irradiação solar. Foi decidido nesta dissertação seguir esta orientação, testando diferentes modelos de céu limpo e nublado, e de extrapolação da irradiação solar, usando como referência os dados meteorológicos medidos em Miranda do Norte a cada minuto durante quase quatro anos. Uma análise estatística foi utilizada para comparação entre os resultados, e um modelo é proposto.

Será dada ênfase na confiabilidade de previsão para 1 dia, uma vez que pretende-se simular a irradiação com horizonte da simulação de 1 dia, 3 dias, e uma semana à frente. Serão determinadas as incertezas das irradiações previstas.

\section{2}

\section{Motivação}

É consolidado na literatura científica hoje, basicamente quase todos os aspectos ligados diretamente à conversão de energia solar em energia elétrica pelo efeito fotovoltaico, que irá ser denominado por geração de energia elétrica fotovoltaica.

É notório e extensivamente explicitados por todos os autores a natureza intermitente de geração de energia elétrica fotovoltaica.

A motivação por trás deste estudo é a sua capacidade de contribuir para o desenvolvimento, formulação e validação de um modelo robusto que possa prever realisticamente a irradiação solar, que pode ser usada para prever a conversão de energia solar em energia elétrica por meio do efeito fotovoltaico, em estrita observação das condições climáticas.

Até o presente momento, a literatura se dedicou a estudar intensivamente a área de geração solar fotovoltaica, porém ainda existem lacunas a serem preenchidas no que diz respeito à previsibilidade da radiação solar, e seu respectivo impacto na geração de energia elétrica. Este fato, em conjunto com as diversas relações de condições atmosféricas, trazem um enorme problema para a implementação efetiva da gestão das redes de energia elétrica, pois todos estes fatores aumentam muito a incerteza associada à produção de energia solar [17], gerando um impacto muito grande na confiabilidade da previsão de produção de energia solar.

Torna-se necessário assim, por questões de controle do sistema elétrico e de gestão das centrais elétricas, encontrar formas de prever a produção a 
partir de variáveis meteorológicas como, por exemplo, velocidade do vento, temperatura ambiente, irradiação solar, pluviosidade, etc. Estas variáveis meteorológicas podem ser usadas para prever a produção energética, o que é um aspecto muito importante, em particular no que diz respeito à participação no mercado diário de energia elétrica.

A liberalização do mercado de energia elétrica, inserido em um modelo de participação diária de mercado de energia, faz com que empresas que produzem e distribuem energia, sobretudo no setor de energia renovável, tenham como objetivo maximizar sua produção, reduzindo custos, impactos ambientais e melhorando sua eficiência. Neste contexto, torna-se fundamental desenvolver estratégias de otimização de geração e transmissão de energia. No que diz respeito a fontes energéticas renováveis, isto só pode ser garantido com exatidão caso seja feita uma previsão realista e confiável da geração que se busca realizar.

Assim, esta dissertação busca avaliar modelos já estabelecidos de previsão, e, utilizando os dados disponíveis, verificar qual o melhor modelo de céu limpo deve ser utilizado de forma a maximizar e otimizar a previsão de geração de energia elétrica fotovoltaica, de forma a conseguir balancear mais eficientemente o fluxo de energia através da rede, estruturando assim a sua participação no mercado.

\section{3}

\section{Objetivos: geral e específicos}

A pesquisa tem como objetivo geral propor um modelo de previsão a curto prazo da irradiação solar a partir de correlações de condições climáticas, tal objetivo visa diminuir as incertezas de previsão da irradiação solar, que pode ser usado para prever a geração fotovoltaica.

Para alcançar este objetivo geral, definem-se os seguintes objetivos específicos, a seguir justificados:

- Prever a irradiação solar, com horizonte da simulação de 1, 3, 5 e 7 dias à frente: A partir destes valores previstos poderão ser feitas comparações em relação aos valores medidos em campo.

- Validar o procedimento escolhido: Por meio de dados medidos em Miranda do Norte será possível validar o procedimento escolhido e o ferramental utilizado, e realizar ajustes.

- Determinar a incerteza da previsão: Essencial para avaliar se o procedimento adotado representa de forma confiável e com exatidão a realidade. Será utilizado o recurso da RMSE para avaliar os modelos, comparando a grandeza medida e a grandeza prevista. As incertezas de previsão serão então estimadas. 


\section{4}

\section{Estrutura da dissertação}

A dissertação encontra-se estruturada em seis capítulos, incluindo esta introdução (capítulo 1).

No capítulo 2, encontra-se todos os conceitos teóricos sobre radiação solar.

No capítulo 3, apresentam-se os conceitos e modelos e metodologia utilizada para prever a radiação solar. Na sequência apresenta um quadro geral com as principais abordagens metodológicas criadas e utilizadas atualmente, assim como sua respectiva qualidade de mensuração e avaliação quanto à geração de energia. O capítulo aborda, ainda, os principais benefícios e barreiras de cada método considerado.

No capítulo 4, será abordado as definições de Céu Limpo, que será de suma importância para o desenvolvimento do modelo de previsão a ser proposto.

O capítulo 5 propõe a sugestão de uma modificação a um modelo já consolidado na literatura para prever a irradiação solar a partir das condições climáticas $^{2}$, de modo a diminuir assim a incerteza de previsão, ressaltando os diferenciais desta nova modelagem, através de extensa revisão, consulta e estudo bibliográfico sobre o tema.

No capítulo 6, apresentam-se e discutem-se os resultados do estudo, de forma a demonstrar a aplicabilidade do modelo assim como sua confiabilidade e a incerteza atrelada a previsão feita e os dados medidos.

Finalmente, no capítulo 7, formulam-se as conclusões da pesquisa e endereçam-se propostas para estudos futuros assim como o aprofundamento de aspectos relevantes que emergirão desta dissertação.

\footnotetext{
${ }^{2}$ Modificações quanto à utilização do modelo de céu limpo para a sua utilização no modelo de previsão de Bindi[21] serão analisadas
} 


\section{2}

\section{Fundamentos Teóricos}

Este capítulo irá apresentar todo o fundamento teórico já consolidado na literatura que será utilizado como base para o desenvolvimento de um modelo de previsão de radiação solar, de forma a dar um embasamento teórico sólido sobre os termos que irão ser abordados, calculados e previstos.

\section{1}

\section{Radiação extraterrestre em uma superfície horizontal}

A radiação extraterrestre, representa, teoricamente, o limite superior da radiação solar disponível na superfície terrestre. A resultante da radiação solar extraterrestre, assim como sua distribuição espectral foram amplamente estudadas no passado, e suas medições foram feitas através de diversos estudos e experimentos.

A constante solar $G_{s c}$, que é a energia do Sol por unidade de tempo recebida em uma área unitária de uma superfície perpendicular à direção de propagação da radiação do Sol à distância média entre o Sol e a Terra, fora da atmosfera, foi fruto de diversas pesquisas.

Antes mesmo de foguetes e naves aeroespaciais, a constante foi estimada através de medições em terra, feitas em montanhas de alta altitude, de modo a estimar assim a transmissão atmosférica. Foi constado assim, que a constante solar seria de $1322 \mathrm{~W} / \mathrm{m}^{2}[22]$.

Mais recentemente, no início da década de cinquenta, com o advento de foguetes aeroespaciais, esta constante foi reavaliada para $1395 \mathrm{~W} / \mathrm{m}^{2}$ [23].

Em 1971, com a disponibilidade de naves que atingissem altitudes altíssimas, balões, e naves aeroespaciais, tal valor foi revisado em um grande estudo no qual puderam estimar, com um erro de $\pm 1,5 \%$ a constante solar $G_{s c}$ em $1353 \mathrm{~W} / \mathrm{m}^{2}[24]$. Vale salientar que nesta época, este valor foi aceito como valor padrão pela NASA[25].

Diversas revisões e novos estudos foram conduzidos até o momento sobre este assunto, desta forma, o valor utilizado neste trabalho para se referir à constante Solar $G_{s c}$ será o valor encontrado por [26], que é de $1367 \mathrm{~W} / \mathrm{m}^{2}$ (dentro de $\pm 1 \%$ ), que, para estudos de engenharia é o mais utilizado e mais aceito[14]. 


\section{2}

\section{A variação da radiação extraterrestre anual}

A variação da radiação solar extraterrestre é influenciada segundo dois principais fatores: A variação da radiação emitida pelo Sol, e o distanciamento entre Sol e Terra.

Para propósitos de engenharia, a energia emitida pelo sol pode ser considerada constante[14].

Porém, a variação da distância entre o Sol e a Terra, levam a variações que devem ser consideradas.

O equacionamento feito por [27], apresentado a seguir, apresenta incerteza de $\pm 0,01 \%[26]$ :

$$
\begin{array}{r}
G_{\text {on }}=G_{\text {sc }}(1,00011+0,034221 \cos (B) \\
+0,001280 \sin (B)+0,000719 \cos (2 B)+0,000077 \sin (2 B))
\end{array}
$$

Onde $G_{o n}$ é a radiação extraterrestre incidente em um plano normal à radiação no enésimo dia do ano, e $\mathrm{B}$ e dado por:

$$
B=(n-1) \times \frac{360}{365}
$$

Onde $\mathbf{n}$ é o dia do ano.

\section{3 \\ Definições}

Massa de $\operatorname{Ar}(\mathrm{m})$, é a razão entre a massa de ar atmosférico atravessado pela radiação direta e a massa de ar que ela atravessaria no momento em que o Sol estivesse diretamente em seu zênite, ou seja, diretamente normal à superfície.

Radiação Direta é a radiação solar recebida do sol que não sofreu mudança de direção pela atmosfera.

Radiação Difusa é a radiação solar recebida do sol após sua direção ter sido modificada pela atmosfera.

Radiação Global é o somatório entre radiação direta e difusa.

Hora Solar é o tempo baseado no movimento angular aparente do sol no céu. 


\section{4}

\section{Cálculo da Hora Solar}

A Hora Solar é a hora utilizada em todas as relações angulares do Sol, e vale salientar que ela não coincide com a hora local. Tendo isto em vista se faz necessário converter a hora local padrão para hora solar utilizando a fórmula proposta por [27]:

$$
H_{\text {Solar }}-H_{\text {Local }}=4 \times\left(L_{s t}-L_{l o c}\right)+E
$$

Onde $\mathbf{E}$, tem o valor formulado por [27],

$$
\begin{array}{r}
E=229,2(0,000075+0,001868 \cos (B) \\
-0,032077 \sin (B)-0,014615 \cos (2 B)-0,04089 \sin (2 B))
\end{array}
$$

Onde Lst é a longitude do meridiano padrão para aquele fuso horário, Lloc é a longitude do lugar em questão expresso em graus oeste, e E é expresso em minutos.

Nesta dissertação, será admitido hora sempre como hora solar, a menos que seja indicado o contrário.

\section{5}

\section{Direção da Radiação Direta}

A relação geométrica entre um plano de qualquer orientação particular em relação ao da Terra em qualquer momento (seja este plano fixo ou se movimentando relativamente à Terra) e a Radiação Direta recebida, que é, a posição do Sol em relação a este plano, pode ser descrita em termos de alguns ângulos[28]:

$\phi$ - Latitude, a localização angular norte ou sul em relação ao equador, sendo norte positivo e sul negativo.

$\delta$ - Declinação, a posição angular do Sol em relação ao meio dia solar, em respeito ao plano do equador, sendo norte positivo e sul negativo.

$\beta$ - Inclinação, o ângulo entre o plano da superfície em questão com a horizontal.

$\gamma$ - Ângulo Azimute de Superfície, é o Angulo entre a normal da superfície e o meridiano local, sendo leste negativo e oeste positivo.

$\omega$ - Hora angular, o deslocamento angular do Sol em relação ao meridiano local em função da rotação do eixo da terra em 15 graus, sendo manhã negativo e tarde positivo. 
$\theta$ - Ângulo de Incidência, o ângulo entre a radiação direta em uma superfície e a sua normal.

$\theta_{z}$ - Ângulo Zênite, o ângulo entre a vertical e a direção da incidência da radiação solar em uma superfície horizontal.

$R_{b}$ - Fator geométrico, a razão da radiação direta numa superfície inclinada a uma superfície horizontal, pode ser calculada de forma exata através da formula de $\theta$ e $\theta_{z}$, da qual obtêm-se a seguinte formulação:

$$
R_{b}=\frac{\cos (\theta)}{\cos \left(\theta_{z}\right)}
$$

A declinação $\delta$, é descrita abaixo pela formulação proposta por [27]:

$$
\begin{array}{r}
\delta=\frac{180}{\pi}(0,006918-0,399912 \cos (B) \\
+0,070257 \sin (B)-0,006758 \cos (2 B) \\
+0,000907 \sin (2 B)-0,002697 \cos (3 B)+0,00148 \sin (3 B))
\end{array}
$$

Vale salientar que esta equação apresenta um erro inferior a 0,035 [26]. As seguintes relações são dadas para os ângulos descritos acima[14]:

$$
\begin{array}{r}
\cos (\theta)=\sin (\delta) \sin (\phi) \cos (\beta)-\sin (\delta) \cos (\phi) \\
\sin (\beta) \cos (\gamma) \\
+\cos (\delta) \cos (\phi) \cos (\beta) \cos (\omega)+\cos (\delta) \sin (\phi) \sin (\beta) \cos (\gamma) \cos (\omega) \\
+\cos (\delta) \sin (\beta) \sin (\gamma) \sin (\omega) \\
\cos \left(\theta_{z}\right)=\cos (\phi) \cos (\delta) \cos (\omega)+\sin (\phi) \sin (\delta)
\end{array}
$$

A hora angular na qual o sol nasce é igual à hora angular do sol poente com sinal oposto, tal relação é dada por [14]:

$$
\cos \left(\omega_{s}\right)=-\tan (\phi) \tan (\delta)
$$

Onde $\omega_{s}$ é a Hora do Angular sol poente.

\section{6}

\section{Radiação extraterrestre em uma superfície horizontal}

A maioria dos cálculos para radiação solar são mais convenientemente feitos utilizando valores de radiação solar extraterrestre, que teoricamente seria a maior radiação possível que estaria disponível se não houvesse atmosfera na Terra.

A todo e qualquer momento em um período entre o nascer e pôr do sol tem-se que a radiação solar incidente em um plano horizontal fora da atmosfera terrestre é dada por: 


$$
G_{0}=G_{\text {on }} \cos \left(\theta_{z}\right)
$$

Desta forma, está parametrizado a radiação solar extraterrestre em função dos dias do ano assim como das horas do dia.

\section{7}

\section{Atenuação Atmosférica da Radiação Solar}

Discussões mais detalhadas sobre este tema foram feitas por [26]. Discussões sobre o espalhamento, que inclui definições e efeitos da cobertura de nuvens foram feitas por [29], [30], e [26], conforme enumerado por [14].

Esta dissertação adotará um modelo ouro de atenuação atmosférica amplamente e extensivamente revisado e utilizado por NREL(National Renewable Energy Laboratory)[31] e SANDIA National Laboratories[32], assim como por diversos outros autores considerados referência no assunto, que é o modelo de Céu Limpo. Mais detalhes sobre este modelo serão abordados nos capítulos a seguir.

A absorção da radiação solar pela atmosfera terrestre é dada principalmente pelo ozônio atmosférico, assim como vapor de água e dióxido de carbono.

Dentre todo o espectro de energia eletromagnética gerada pelo Sol (0,5-2,5 $\mu \mathrm{m})$, a Teoria do Espalhamento afirma que comprimentos de onda menores sofrem maiores espalhamentos[14], como a radiação difusa tende a ter comprimentos de onda menores ela é mais absorvida pela atmosfera. Devido a este fenômeno, é que pode-se perceber que a cor do céu é azul.

Devido a atenuação atmosférica, e do ponto de vista das aplicações para a energia solar, somente o espectro contido entre 0,29 e 2,5 $\mu \mathrm{m}$ são considerados.

\section{8}

\section{Estimativa da média diária de radiação solar incidente}

É possível usar relações empíricas para estimar a radiação solar a partir de horas de insolação ou nebulosidade. Dados de cobertura de nuvem são amplamente disponíveis, porém são baseados em estimativas visuais e provavelmente são menos úteis, pois estatísticamente não apresentam uma boa correlação com a irradiação solar incidente como a correlação apresentada por dados de horas de insolação e a irradiação solar incidente[14].

\section{9}

\section{Radiação de céu limpo}

Os efeitos dos fenômenos de espalhamento e absorção atmosférica variam quando as condições atmosféricas mudam; por isto é necessário definir-se um padrão de céu limpo para que posteriormente seja possível calcular a radiação 
horária a ser recebida em uma superfície horizontal como função do ângulo Zenite do Sol.

Nesta pesquisa foi utilizado como padrão um dos modelos de céu limpo estabelecido pelo SANDIA National Laboratories[32], que será detalhadamente explicado no capítulo seguinte. 


\section{3 \\ Metodologia e Modelos de Previsão}

Este capítulo irá apresentar os modelos e metodologias utilizadas para prever a radiação solar, assim como comparar as principais abordagens metodológicas quanto a sua respectiva qualidade de mensuração e previsão, assim como seus respectivos benefícios e barreiras.

\section{1}

\section{Análise do erro e incertezas}

Para avaliar o erro entre os diversos modelos analisados utilizou-se o recurso da raiz do erro médio quadrático (RMSE).

Para realizar a análise da incerteza da previsão, deve-se considerar os principais fatores que irão influenciar diretamente o modelo de previsão proposto. Como o modelo de previsão proposto no Cap. 5 opera apenas com duas grandezas: Irradiação solar e temperatura ambiente. Deve-se analisar a influência da incerteza destes dois parâmetros na previsão feita.

O medidor de temperatura utilizado foi um Termohigrômetro modelo HMP155, que apresenta incerteza de 0,7\%[33]. Para medir a irradiação solar global foi utilizado o Piranômetro CMP21, que apresenta incerteza de 1,4\%[34].

De posse de todos os fatores que podem então influenciar a incerteza de previsão, deve-se realizar o cálculo da incerteza combinada, que deve ser caracterizada pelo valor numérico obtido aplicando-se o método usual para a combinação de variâncias. A incerteza combinada e seus componentes devem ser expressos na forma de "desvios-padrão"[35]. Porém, como será mostrado no Cap. 6, o erros e incertezas típicas do modelo de previsão proposto neste trabalho apresentam incertezas da ordem de 12-24\%, desta forma, neste nível de análise de incertezas, pode-se considerar a contribuição das incertezas do piranômetro e do termohigrômetro desprezíveis.

\subsection{1} RMSE

Para avaliar os modelos foi utilizado o recurso de análise da raiz do erro médio quadrático (RMSE), que pode ser facilmente calculado segundo os seguintes passos: 
Primeiro calcula-se o Erro $_{\text {Quad }}$ :

$$
\text { Erro }_{\text {Quad }}=\left[\left(\text { Valor }_{\text {Previsto }}-\text { Valor }_{\text {Medido }}\right) \times 100\right]^{2}
$$

Onde Erro $_{\text {Quad }}$ é o quadrado da diferença entre o valor previsto e o valor de referência, que é o valor medido em campo.

Com isto, calcula-se o erro médio quadrático, que é dado por:

$$
\text { Erro }_{\text {MedioQuad }}=\frac{\sum_{i=1}^{n} \text { Erro }_{Q u a d} i}{n}
$$

De posse do Erro $_{\text {MedioQuad }}$ extrai-se sua raiz quadrada, e assim obtem-se a raiz do erro médio quadrático.

$$
R M S E=\sqrt{\text { Erro }_{\text {MedioQuad }}}
$$

Posteriormente, quando for abordado o conceito de horizonte de previsão, para o horizonte de 1 dia, realiza-se o cálculo RMSE com $n$ equivalendo a quantidade de dias a serem analisados (no caso de um ano $n=365^{1}$ ), com o Erro $_{\text {Quad }}$ sendo calculado em função das médias dos valores diários.

Para horizontes de 3, 5 e 7 dias, o Erro $_{\text {Quad }}$ é calculado respectivamente utilizando valores médios de 3,5 e 7 dias. Desta forma, $n$ corresponde ao número de observações médias de 3, 5 ou 7 dias contidas no número total de dias a serem analisados (no caso de um ano, $n$ corresponde a respectivamente 121, 73 e 52).

\subsection{2}

\section{Incerteza de Previsão}

Para realizar a avalição das incertezas de previsão da irradiação solar será utilizado a distribuição t-STUDENT, sempre para o nível de confiança de $95,45 \%$.

Os dados históricos obtidos pela estação meteorológica de Miranda do Norte são de 4 anos (cerca de 1460 dias), será trabalhado e analisado os erros e incertezas de previsão em blocos anuais. O fator de abrangência ( $k$ ) a ser utilizado, é obtido da distribuição t-STUDENT para um nível de confiança de $95,45 \%$.

Desta forma tem-se:

$$
U=k u_{c}
$$

Onde U é a incerteza expandida e $u_{c}$ é a incerteza padrão combinada (que é o RMSE da previsão feita).

${ }^{1} n=365$ pois os dados aquisitados a cada minuto foram tratados e compilados em dados de médios diários 
Pode-se afirmar então que existe $95,45 \%$ de probabilidade de que o valor verdadeiro $\mu$ (que se deseja prever) esteja então na seguinte faixa:

$$
x_{i}-U \leq \mu \leq x_{i}+U
$$

Ou então $x_{i} \pm U$ para $k=2$, ou $95,45 \%$ de nível de confiança.

Onde $x_{i}$ é o valor previsto, e U a incerteza da previsão.

\section{2}

\section{Modelos mais utilizados}

Após ampla análise e estudo da literatura científica no que diz respeito à modelos utilizados para a previsão da irradiação solar, pode-se dizer que muitos métodos, assim como diferentes modelagens vem sendo abordadas por diversos autores desde a década de 30 .

Redes Neurais Artificiais muitas vezes são utilizadas para prever e estimar a radiação solar e a transmitância atmosférica, porém apresentam RMSE da ordem de 20 a $50 \%$ para os valores previstos[36].

Modelos baseado em horas diárias de insolação também são utilizados para o mesmo propósito, com RMSE da ordem de 20\%[37].

Relações estatísticas entre a radiação solar e a umidade relativa foi correlacionada em regiões tropicais, com erro padrão de 14\%[20].

Dentre as mais promissoras estratégias de relacionar a radiação solar, e por consequência, a transmitância atmosférica com variáveis meteorológicas, se destacam as correlações de Bennet, que correlacionam horas de insolação com a incidência de radiação solar que apresenta RMSE de 10 \%[18] para valores médios mensais, e a equação de Angstrom, que correlaciona temperatura ambiente e umidade relativa com a incidência de radiação solar, que apresenta RMSE amplamente dependente da altitude, podendo variar de 10 a 25\%[38]. Estas duas equações, apesar de apresentarem erros relativamente baixos, a sua implementação se torna muito difícil devido ao fato de que para o seu correto funcionamento é necessário diversos ajustes, o que se torna um processo não trivial.

O método dos Mínimos Quadrados Ordinários, que utiliza uma regressão linear simples, é baseado em adquirir informações sobre o comportamento temporal passado da variável a ser estudada (irradiação solar), para extrapolar um valor para a predição futura da mesma. Este método pode ser que apresente valores interessantes para o estudo proposto. Devido à falta de informações na literatura científica que utilize este método para modelar e prever a irradiação solar, um dos pontos que será abordado durante esta dissertação será a implementação e análise deste método. 
Dentre todos os modelos extensivamente estudados e abordados pela literatura científica, destaca-se, o modelo proposto por Bindi[21], que estima a radiação global diária a partir da temperatura do ar e apresenta RMSE da ordem de $12 \%$.

\subsection{1}

\section{Escolha do melhor método}

Como enunciado anteriormente, correlacionar radiação incidente e transmitância atmosférica com variáveis meteorológicas não é um processo simples e trivial.

A partir de ampla análise dos modelos e equacionamentos propostos pela literatura, decidiu-se optar por utilizar o método proposto por Bindi, M., \& Miglietta, F. (1991)[21].

A escolha deste método se deu devido ao alinhamento do método para com as variáveis obtidas através das medições feita na estação meteorológica instalada em Miranda do Norte, assim como pelo fato de este modelo não necessitar de ajustes para funcionar, e devido ao fato de dentre todos os demais métodos e modelos este apresentar o menor RMSE dentre todos. Este modelo, assim como uma modificação dele que será proposta no Capítulo 5, serão implementados, validados e terão suas confiabilidades de previsão avaliadas.

\section{3}

\section{Previsão da transmitância atmosférica}

O modelo escolhido [21], se baseia em caracterizar quais os dias apresentam condição de céu limpo e quais dias apresentam condição de totalmente nublado (overcast), assim como os dias com condições intermediárias. Realizase uma forma de regressão baseada em dados físicos, empíricos, e correlações entre a temperatura ambiente e a transmitância atmosférica para prever assim a transmitância de dias com condições intermediarias. Para dias de Céu Limpo, e para dias totalmente nublados (overcast) são utilizados cálculos já consolidados e extensivamente revisados pela literatura.

A partir de dados de previsão de transmitância, facilmente consegue-se calcular e prever radiação incidente.

\subsection{1}

\section{O fenômeno físico}

A transmitância atmosférica é a razão entre o fluxo de irradiação transmitido pela atmosfera, e o fluxo de irradiação recebido pela atmosfera. Ela pode ser expressa da seguinte forma: 


$$
K=\frac{R}{G_{0}}
$$

Onde $\mathrm{K}$ é a transmitância atmosférica, $\mathrm{R}$ é a radiação líquida no solo terrestre após o processo de atenuação atmosférica (que varia de acordo com com as condições atmosféricas e geográficas), e $G_{0}$ é a radiação extra terrestre incidente.

A teoria por trás do modelo de previsão utilizado é explicada devido ao fato de que a radiação solar que chega na superfície da Terra, depende da transmitância atmosférica. Durante o dia, a superfície terrestre absorve a radiação solar, e assim a temperatura do solo e a temperatura ambiente aumentam.

Com isto, os dias claros são geralmente caracterizados por um aumento na diferença entre a temperatura noturna e diurna. Em dias nublados, a nebulosidade diminui a radiação incidente durante o período diurno, e também restringe a dissipação térmica durante a noite, desta forma, a diferença entre a temperatura noturna e diurna é reduzida.

Portanto, a diferença entre o alcance termal de dois dias consecutivos é relacionada com a diferença da transmitância média destes mesmo dias[21].

\subsection{2}

\section{Identificação de dias de Céu Limpo e dias Totalmente Nublados (Over- cast))}

Primeiramente, dias em que a probabilidade de ocorrerem condição de céu limpo e totalmente nublados (overcast) são identificados.

De acordo com a satisfação de todos os seguintes parâmetros, dias de céu limpo podem ser identificados[21]:

- Aumento da máxima temperatura em relação à máxima temperatura do dia anterior

- Decaimento da mínima temperatura em relação à mínima temperatura do dia anterior

- A diferença de temperatura $\left(T_{\max }-T_{\min }\right)$ é maior que a média móvel ${ }^{2}$ de temperatura dos últimos 30 dias.

Para a identificação de dias totalmente nublados (overcast) pode-se definir condições opostas das declaradas acima.

Uma vez identificado os dias, utilizam-se as formulações que estão descritas no Capítulo 5 para realizar o cálculo das respectivas transmitâncias dos dias de céu limpo e totalmente nublados (overcast).

\footnotetext{
${ }^{2}$ Conforme o conceito de média móvel descrito por Kendall, M. G., \& Alan, S. (1961)[39]
} 


\subsection{3}

\section{Previsão da transmitância média para dias Intermediários}

Quando um dia não apresenta nem condição característica de céu limpo, nem de totalmente nublado (overcast), apresentando assim condições intermediárias, que podem ser virtualmente qualquer combinação encontrada entre estes dois extremos. Nestes casos, o seguinte procedimento [21] é utilizado:

O modelo considera que quanto maior a variação da diferença de temperatura de dois dias consecutivos, maior será a variação da transmitância média, ou, em outras palavras, que a diferença entre a transmitância atmosférica de dois dias consecutivos $\left(D K=K_{n}-K_{n-1}\right)$, é diretamente relacionada com a diferença entre as diferenças de temperatura destes dias $\left(D D T=D T_{n}-D T_{n-1}\right)[21]$.

$\mathrm{O}$ valor de DK, em função de $D D T_{n}$ e $K_{n-1}$ é representado da seguinte forma:

$$
D k_{n}= \begin{cases}K_{\text {over }}-K_{n-1} & \text { se } D D T_{n}<D D T_{\text {low }}, \\ \frac{K_{\text {over }}-K_{n-1}}{D D T_{\text {low }}} D D T_{n} & \text { se } D D T_{\text {low }} ₹ D D T_{n} ₹ 0, \\ \frac{K_{C L}-K_{n-1}}{D D T_{\text {upp }}} D D T_{n} & \text { se } 0<D D T_{n} ₹ D D T_{\text {upp }}, \\ K_{C L}-K_{n-1} & \text { se } D D T_{n}>D D T_{\text {upp }} .\end{cases}
$$

Onde $n$ é o tempo em dias, $K_{\text {over }}$ é a transmitância de céu totalmente nublado (overcast), $K_{C L}$ é a transmitância de céu limpo para o dia $n, D D T_{\text {low }}$ e $D D T_{\text {upp }}$ são respectivamente, os valores mínimos e máximos de $D D T$.

Para Miranda do norte, $D D T_{\text {low }}$ e $D D T_{\text {upp }}$ foram calculados com base em dados históricos do valor médio de $D D T$ para cada respectivo ano.

Desta forma, a transmitância do Dia t pode ser calculada utilizando a Eq.3-8 [21]:

$$
K i_{t}=K_{t-1}+D K_{t}
$$




\section{4}

\section{Céu Limpo}

Este capítulo irá apresentar as diferentes formulações de céu limpo, a implicação de uso de cada uma delas, assim como benefícios e possíveis impecílios para suas respectivas implementações. Será apresentado também um modelo para caracterização de dia totalmente nublado (overcast), que é a condição exatamente oposta à condição de céu limpo.

\section{1}

\section{Definição, aplicabilidade e classificação dos modelos}

Modelos de Céu Limpo estimam a radiação incidente na superfície terrestre sob condições de ausência de nuvens como função do ângulo de elevação solar, altitude do local, concentração de aerossol, pressão de vapor e várias outras condições atmosféricas[32].

Mesmo em dias sem nuvens, de forma geral, cerca de $25 \%$ da radiação extraterreste do sol é absorvida e espalhada pela sua passagem pela atmosfera[32].

A principal variável utilizada para a modelagem de Céu Limpo é o ângulo zênite $\operatorname{solar}\left(\theta_{z}\right)$, definido anteriormente pela Eq. 2-8:

Modelos de Céu Limpo são utilizados para modelar a incidência máxima de irradiação solar após a atenuação atmosférica, ou seja, eles fornecem dados sobre a máxima incidência de irradiação solar na superfície Terrestre.

Para escolha do modelo de céu limpo mais adequado para este estudo foram analisados na literatura existente os modelos mais utilizados, assim como seus respectivos erros, confiabilidades, limitações, restrições, praticidade de implementação e usabilidade, a fim de assim obter um arcabouço teórico sólido sobre o tema, que será uma das bases utilizadas para a modelagem física desenvolvida neste trabalho.

Sandia National Laboratories, que opera para o Departamento de Energia dos Estados Unidos da América apresenta um grande histórico de estudos e análises sobre o tema de Modelos de Céu Limpo, e em seus estudos apresentam mais de 300 anos de dados[32].

Segundo Sandia National Laboratories, os modelos de Céu Limpo são classificados em três categorias, sendo eles: Modelos Muito Simples, Modelos Simples, Modelos Complexos. 
Modelos Muito Simples utilizam apenas dados geométricos, eles modelam a atenuação atmosférica apenas como função do ângulo zênite. Alguns exemplos de modelos muitos simples são os definidos por Kasten-Czeplak[40], Haurwitz[41][42] e Robledo-Soler [43].

Modelos Simples, além do ângulo zênite levam em consideração alguns parâmetro atmosféricos, assim como pressão, temperatura, umidade relativa, concentração de aerossóis e etc.. Dentre os modelos simples, o mais destacado na literatura é o modelo de Ineichen e Perez[44].

Modelos Complexos levam diversos outros fatores atmosféricos para a realização de seus cálculos, assim como concentração de ozônio, precipitação de agua, entre outras diversas entradas, que por vez pode se tornar impecílios para seu uso, pois tais dados muitas vezes não são obtidos facilmente. Exemplos de modelos complexos amplamente utilizados são as modelagens de Bird[45] e REST2[46].

\section{2}

\section{Escolha do modelo mais adequado}

Segundo o Sandia National Laboratories, a precisão não é fortemente dependente do modelo escolhido, e deve ser selecionado o modelo mais facilmente implementável ou que apresente maior quantidade de parâmetros disponíveis. Então, para muitas aplicações, modelos simples de céu limpo podem ser adequados[32].

Levando em conta os parâmetros monitorados no sítio estudado neste trabalho, assim como a facilidade de implementação dos modelos, optar por utilizar um modelo muito simples pode vir a ser uma escolha trivial, porém através de cálculos de desempenho de cada modelo, assim como as posteriores análises do erro, pode-se perceber que a escolha do modelo de céu limpo mais adequado para conseguir prever de forma ótima a irradiação solar não é uma tarefa tão simples como antes pensado ${ }^{1}$.

Modelos que levam em conta todos os parâmetros atmosféricos são ligeiramente mais precisos que os demais modelos, porém precisões comparáveis podem ser obtidas através da utilização de alguns modelos mais simples[32]. Desta forma, mesmo utilizando uma modelagem "simplória" pode-se conseguir representar de forma precisa a radiação em questão.

A formulação de céu limpo de Haurwitz apresenta um erro RMSE de 6,6\%. Este erro apresenta-se altamente comparável até mesmo com os modelos mais complexos citados anteriormente[47].

\footnotetext{
${ }^{1}$ Mais detalhes serão abordados nas subseções 6.1 .1 e 6.1 .2
} 
Dentre os modelos muito simples que descrevem a irradiação para a condição de dias limpos, tem-se o modelo de Kasten-Czeplak[40], modelo de Robledo-Soler[43], e modelo de Haurwitz[41][42], que possuem, respectivamente, RMSE de $18 \%, 7,3 \%$ e $6,6 \%$ [32].

Todos os modelos muito simples utilizam como entrada apenas o ângulo zênite $\left(\theta_{z}\right)$.

O modelo de Ineichen e Perez[44], é considerado como um modelo simples, pois além do ângulo zenite, ele leva em conta três outros fatores (massa de ar $A_{M}$, Turbidez $T_{L}$ e elevação do local). Este modelo apresenta um RMSE de $5 \%[32]$.

Dentre os modelos complexos, se destacam os modelos de Bird[45], e o modelo REST2[46], estes modelos utilizam diversas outras varíaveis como entrada, como por exemplo a preciptação de água, pressão, albedo de superfície, comprimento de aerosóis óticos, umidade, temperatura, caminho de comprimento reduzido vertical de ozônio, expoentes de comprimento de onda de Angstrom, turbidez, entre outros. Estes modelos possuem respectivamente RMSE de $5 \%$ e $4,7 \%[32]$.

A implementação de modelos complexos de céu limpo para uma dada localidade é um processo que consome muito tempo, e estes modelos são amplamente dependentes de medições locais[47]. Desta forma, para muitas aplicações, modelos simples de céu limpo podem ser úteis[48].

Serão abordados três modelos de céu limpo amplamente citados na literatura científica. A escolha do modelo mais adequado será justificada através da avaliação do erro do modelo em sí, do erro de previsão da irradiação solar que a utilização de tal modelo acarreta, assim como também através da avaliação de possíveis erros sistemáticos que cada modelo possa implicar.

Com isto, levando em consideração a viabilidade de implementação de cada modelo, assim como os erros apresentados, foram escolhidas três formulações de céu limpo: Formulação de Haurwitz, de Kasten e de Ineichen, que serão detalhadamente descritas na seção 4.3.

\section{3}

\section{Formulação dos modelos de Céu Limpo}

A formulação de Céu Limpo descrita por Haurwitz[41][42] é dada por:

$$
R_{\text {CéuLimpo }}=1098 \cos \left(\theta_{z}\right) e^{-\frac{0,057}{\cos \left(\theta_{z}\right)}}
$$

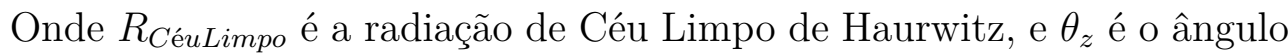


zênite do Sol.

A formulação de Céu Limpo descrita por Kasten-Czeplak[40], conforme é utilizada por Bindi[21], é dada por:

$$
K_{\text {CéuLimpo }}=0,83 e^{\frac{-0,026 T_{L}}{\sin (\alpha)}}
$$

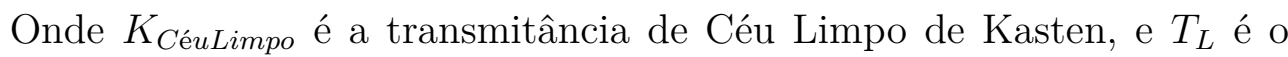
fator de turbidez estimado para o dado local.

O fator de turbidez $T_{L}$, por sua vez, pode ser descrito em função de duas constantes: A primeira constante é b, com valor 0,2 (sítio industrial), e $w_{2}$ com valor de 4,5 (clima tropical-semi umido)[49].

O fator de turbidez $T_{L}$, é estimado segundo [50], da seguinte forma:

$$
T_{L}=\frac{\alpha+85}{39,5 e^{-w_{2}}+47,4}+0,1+\left(16+0,22 w_{2}\right) b
$$

Onde $\alpha$ é o ângulo de Elevação Solar, que é o complemento do ângulo Zênite.

Desta forma obtem-se a transmitância de céu limpo de Kasten[40]².

A formulação de Céu Limpo descrita por Ineichen[44], e revisada por [32], descreve a radiação de céu limpo em função da Massa de $\operatorname{Ar} A_{M}$ (calculada pela Eq. 4-5), $T_{L}$ (calculado pela Eq. 4-3) e mais quatro variáveis:

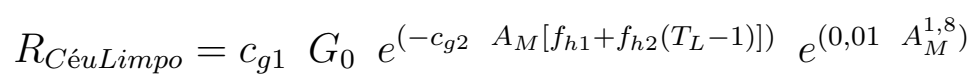

Com $c_{g 1}=5,09 \times 10^{-5} h+0,868, c_{g 2}=3,92 \times 10^{-5} h+0,0387$, $f_{h 1}=\frac{-h}{8000}$ e $f_{h 2}=\frac{-h}{1250}$. Onde h é a elevação local $(h \simeq 50 \mathrm{~m})$.

$A_{M}$ é estimado a partir do equacionamento proposto por [52]:

$$
A_{M}=\frac{1}{\cos \left(\theta_{z}\right)+0,00176759 \theta_{z}\left(94,37515-\theta_{z}\right)^{-1,121653}}
$$

${ }^{2}$ baseado na modificação da equação Lei de Beer[51], da mesma forma que foi utilizado por [21]. 


\section{4}

\section{Dias Totalmente Nublados (Overcast)}

Neste trabalho será denotado por dia totalmente nublado (overcast), aquele em que o céu está totalmente nublado, ou seja, totalmente encoberto nas camadas altas, médias e baixas da atmosfera. Desta forma, pode-se afirmar que este cenário apresenta a maior atenuação possível que a radiação solar poderá sofrer. Assim, por convenção, pode-se dizer que um dia totalmente nublado (overcast), é totalmente o cenário oposto de um dia de céu limpo.

Nuvens presentes nas diversas camadas da atmosfera contribuem para a atenuação da radiação solar de diversas maneiras[53]. Como para os propósitos deste trabalho apenas a condição de dia totalmente nublado é de interesse, será dado enfoque apenas para a condição de céu 100\% encoberto.

Turner \& Abdulaziz desenvolveram um equacionamento empírico [54] que calcula a transmitância para dias nublados, baseado apenas no ângulo de elevação solar, e no percentual de cobertura de nuvens. Como o interesse é apenas formalizar a condição de céu totalmente nublado (overcast), aplicouse fator de 1,0 para a constante de cobertura de nuvens da formulação [54], obtendo assim:

$$
K_{\text {nublado }}=a+b^{2} \sin (\alpha)+c^{2}+d \sin (\alpha)
$$

Onde $K_{\text {nublado }}$ é a transmitância para dias totalmente nublados (overcast), $\alpha$ é o ângulo de elevação solar, a, b e c são coeficientes de regressão préestabelecidos ${ }^{3}$.

\footnotetext{
${ }^{3}$ Os coeficientes de regressão são pré-estabelecidos para cada intervalo do Ângulo de Elevação Solar $(\alpha)[53]$
} 


\section{5}

\section{Modelagem}

Este capítulo irá apresentar a modelagem feita para prever a irradiação solar. Será abordado desde à obtenção de dados in loco, tratamento de dados e posterior programação elaborada, assim como todos os cálculos, métodos e metodologias envolvidas em modelar um modelo para previsão de irradiação solar.

\section{1}

\section{Obtenção de dados}

Na cidade de Miranda do Norte foi instalada uma pequena base para aquisição de dados meteorológicos pertinentes à geração de energias térmica e fotovoltaica com o intuito de conseguir a partir destes dados estimar a radiação solar incidente e utilizar este parâmetro como base para cálculos de geração fotovoltaica.

A estação meteorológica instalada contempla medições e aquisições de dados a cada minuto, em tempo real, desde janeiro de 2017.

Todos os dados foram salvos em arquivos (CSV) comma-separated values, pós processados e conferidos.

As seguintes variáveis foram medidas e obtidas:

- Dia, hora e minuto

- Pressão atmosférica

- Temperatura ambiente

- Umidade relativa

- Radiação Global

- Direção e velocidade do vento

Como os dados foram obtidos minuto a minuto, para todos os dias do ano, a base de dados ficou bem extensa, contendo cerca de 518 mil aquisições por ano, para cada uma das variáveis citadas acima. Por se tratar de uma base de dados grande, tanto em entrada quanto em tamanho de arquivo para se trabalhar em ambiente matemático e computacional, decidiu-se importar o banco de dados para o ambiente de programação Python em conjunto com 
o pacote Pandas para realizar a vasta maioria dos cálculos presentes neste trabalho.

Com a base de dados inserida no ambiente de programação, a aplicação dos conceitos e modelos matemáticos propostos fica trivial.

\section{2}

\section{Cálculos primários}

Com base nos conceitos descritos nos capítulos anteriores, em toda a base teórica consolidada na literatura, e nas funções analíticas desenvolvidas que foram descritas, elucidam-se os seguintes objetivos:

1. Calcular a radiação extraterreste incidente em um plano normal à radiação para todos os dias do ano.

2. Delimitar, para cada dia do ano, qual o horário exato em que o sol se nasce e se põe

Para realizar o cálculo da radiação incidente, sabe-se que a latitude $(\phi)$ de Miranda do Norte é: $3^{\circ} 34^{\prime} 9^{\prime \prime}$.

Então, a partir da constante da radiação extraterrestre $G_{s c}$, que vale $1367 \mathrm{~W} / \mathrm{m}^{2}$, e através da equação $2-10$, calcula-se $G_{0}$, com do dia do ano $\mathbf{n}$.

Obtêm-se assim, para toda nossa base dados, a radiação extraterrestre incidente em cada dia do ano.

Com o horário em que o Sol nasce e se põe, pode-se determinar a duração da luz solar em cada dia do ano. Para isto, deve-se utilizar o conceito de Hora Solar e Hora angular( $\omega)$, que são derivados da hora local, da latitude e da longitude. Para toda a base de dados calculou-se a Hora Solar e Hora angular.

Vale salientar, que a Hora Solar é o padrão utilizado para representar o tempo em todas as relações de angulares do Sol[14]; portanto daqui em diante, a menos que seja especificado o contrário, quando for abordado o termo hora, é suposto que se trata da Hora Solar.

\section{3}

\section{Cálculo da Transmitância Real (analítica)}

De posse da radiação extraterrestre incidente(calculada), e da radiação global(medida), realizou-se o cálculo da transmitância atmosférica real para Miranda do Norte baseado nos dados de radiação medidos. Assim segundo a Eq. 3-6 tem-se:

$$
K_{\text {real }}=\frac{R_{\text {adiacaoMedida }}}{G_{0}}
$$


Onde $K_{\text {real }}$ é a transmitância atmosférica real, analítica, e $R_{\text {adiacaoMedida }}$ é a radiação medida em campo, e $G_{0}$ é a radiação extraterrestre.

\section{4}

\section{Cálculo da Transmitância de Céu Limpo}

De posse das formulações de Céu Limpo contidas na seção 4.3, foi calculado para todos os dias da base de dados de Miranda do Norte as transmitâncias atmosféricas respectivas ao melhor cenário meteorológico para cada dia do ano, que pode ser descrito por um céu que se apresenta ausente de nuvens, e, assim, apresenta as melhores condições atmosféricas para que a radiação extraterrestre seja aproveitada.

Vale salientar que de posse da transmitância, facilmente pode-se achar a radiação incidente através da Eq. 3-6, assim como o contrário também é possível. Este conceito foi aplicado para toda a base de dados.

\section{5}

\section{Cálculo da Transmitância de Céu Totalmente Nublado (Overcast)}

Da mesma forma que se fez necessário abordar o melhor cenário atmosférico, também é preciso e calcular o pior caso que pode-se presenciar respectivo às condições da atmosfera, que é encontrado em dias totalmente nublados e com alta nebulosidade em todas as camadas atmosféricas, tal situação é calculada a partir da Eq. 4-6:

Da Eq. 4-6, aplicando-se os coeficientes de regressão pre-estabelecidos para cada intervalo do ângulo de Elevação solar $(\alpha)$ tem-se os valores de $\left(K_{\text {nublado }}\right)$, que é a transmitância correspondente para os dias totalmente nublados (overcast):

$$
K_{\text {nublado }}= \begin{cases}0.3080-1.165 \sin (\alpha)-0.0586+1.0743 \sin (\alpha) & \text { se } 0>\alpha<20, \\ 0.5695-0.1065 \sin (\alpha)-0.4755+0.2809 \sin (\alpha) & \text { se } 20>\alpha<40, \\ 0.7862+0.2736 \sin (\alpha)-0.6943-0.0467 \sin (\alpha) & \text { se } 40>\alpha<60, \\ 0.6423+0.9109 \sin (\alpha)-1.2873+0.1222 \sin (\alpha) & \text { se } 60>\alpha<90 .\end{cases}
$$

De posse da transmitância, calcular a radicação incidente em dias totalmente nublados (overcast) torna-se trivial através da Eq. 3-6:

$$
R_{\text {adiacaoNublado }}=K_{\text {nublado }} G_{0}
$$




\section{6}

\section{Previsão da radiação no nível do solo}

A radiação solar que chega ao nível do solo depende da latitude, longitude, transmitância atmosférica, dia e hora. Porém, com as definições feitas até o presente momento, pode-se dizer que a radiação solar incidente no nível do solo é uma função apenas da variação da transmitância atmosférica, pois, através de todas as parametrizações feitas, todas as demais variáveis são conhecidas e foram calculadas.

Desta forma para conseguir estimar ou prever a radiação global incidente, basta apenas conseguir um modelo que parametrize toda e qualquer variação de transmitância atmosférica.

\subsection{1}

\section{Modelos utilizados}

O modelo de previsão de Bindi[21] foi o escolhido para parametrizar a radiação, e assim prever a radiação global no nível do solo, pois como descrito no Capítulo 3, este é modelo mais adequado.

Foram aplicadas ao modelo de previsão de Bindi as três formulações de céu limpo contidas na seção 4.3 . A confiabilidade da utilização de cada formulação de céu limpo para a previsão será mostrada no Capítulo 6 .

Também utilizou-se um modelo de extrapolação pelo métodos dos Mínimos Quadrados Ordinários (OLS) de primeira ordem para prever a radiação solar global, uma vez que a utilização de polinomios de ordens superiores claramente não apresentam nenhuma relação com o processo físico, além do fato que a implementação de graus superiores em testes realizados mostrou uma destreza infinitamente menor no que diz respeito à previsão.

Para todas as modelagens, calculou-se o RMSE de suas respectivas previsões diárias para cada ano, assim como os RMSE para as respectivas médias de radiação solar para os períodos de 3, 5 e 7 dias à frente.

Os resultados serão apresentados no Capítulo 6. 


\section{6 \\ Resultados}

Este capítulo contém os resultados obtidos por cada formulação de céu limpo que se utilizou, e também os resultados obtidos pelo Modelo Proposto para prever irradiação solar para diferentes horizontes de tempo $(1,3,5 \text { e } 7 \text { dias })^{1}$ de previsão, tanto para o método de extrapolação por mínimos quadrados ordinários, quanto para a previsão desenvolvida a partir da temperatura ambiente e transmitância (Modelo Proposto).

\section{1}

\section{Previsão em função do modelo de céu limpo escolhido}

Para cada formulação de céu limpo, obtem-se um resultado de previsão diferente, isto se dá pois o método de previsão utilizado se baseia em uma formulaçao de céu limpo para realizar a previsão.

A comparação da previsão um dia à frente utilizando diversas formulações de céu limpo em conjunto com o método de previsão proposto por Bindi[21] será avaliada na sessão 6.1.1.

\subsection{1}

\section{Análise dos erros de previsão}

Para cada modelo de céu limpo escolhido neste trabalho, seu respectivo valor foi inserido dentro do modelo de previsão sugerido por Bindi[21]. Obtiveram-se assim 03 valores de previsão distintas, cada um respectivo ao modelo de céu limpo a ser utilizado.

O erro, assim como a confiabilidade da utilização de cada modelo de céu limpo inserido no contexto do modelo de previsão sugerido por Bindi[21] foram calculados de acordo com a seção 3.1.

Apresentam-se abaixo tabelas comparativas entre a utilização de três modelos de céu limpo acoplados à metodologia de previsão proposta para o horizonte de 1 dia à frente:

\footnotetext{
${ }^{1}$ Os valores de RMSE obtidos para os diferentes horizontes temporais correspondem aos erros da previsão da média para cada dado período.
} 
Tabela 6.1: Comparativo de erros de previsão - Ano 2017

\begin{tabular}{ccc}
\hline Modelo de & RMSE & $\begin{array}{c}\text { Incerteza [\%] para } \\
\text { Céu Limpo }\end{array}$ \\
{$[\%]$} & $95,45 \%$ de confiabilidade \\
\hline Haurwitz & 17,68 & 35,36 \\
Kasten & 12,63 & 25,26 \\
Ineichen & 11,96 & 23,93 \\
\hline
\end{tabular}

Tabela 6.2: Comparativo de erros de previsão - Ano 2018

\begin{tabular}{ccc}
\hline Modelo de & RMSE & $\begin{array}{c}\text { Incerteza [\%] para } \\
\text { Céu Limpo }\end{array}$ \\
{$[\%]$} & $95,45 \%$ de confiabilidade \\
\hline Haurwitz & 17,42 & 34,85 \\
Kasten & 12,28 & 24,56 \\
Ineichen & 11,61 & 23,22 \\
\hline
\end{tabular}

Tabela 6.3: Comparativo de erros de previsão - Ano 2019

\begin{tabular}{ccc}
\hline Modelo de & RMSE & $\begin{array}{c}\text { Incerteza [\%] para } \\
\text { Céu Limpo }\end{array}$ \\
\hline \%] & $95,45 \%$ de confiabilidade \\
\hline Haurwitz & 63,32 & 126,64 \\
Kasten & 12,57 & 25,14 \\
Ineichen & 11,86 & 23,71 \\
\hline
\end{tabular}

Tabela 6.4: Comparativo de erros de previsão - Ano 2020

\begin{tabular}{ccc}
\hline Modelo de & RMSE & $\begin{array}{c}\text { Incerteza [\%] para } \\
\text { Céu Limpo }\end{array}$ \\
{$[\%]$} & $95,45 \%$ de confiabilidade \\
\hline Haurwitz & 35,38 & 70,75 \\
Kasten & 12,10 & 24,21 \\
Ineichen & 11,26 & 22,52 \\
\hline
\end{tabular}

Percebe-se que a utilização do modelo de céu limpo muito simples que é descrito por Haurwitz apresenta um grande erro e uma incerteza elevada, já o modelo de Kasten, que também é considerado como um modelo de céu limpo muito simples apresenta erro e confiabilidade mais dentro do aceitável. 
O erro e a incerteza obtida pela utilização do modelo de céu limpo considerado como um modelo simples, o modelo de Ineichen, é o que apresentou melhores valores no que diz respeito aos erros e incertezas de previsão.

Pela análise dos erros respectivos à utilização de cada modelo de céu limpo percebe-se que há erros sistemáticos atrelados a utilização de cada modelo, o modelo de céu limpo que minimiza tais erros, assim como minimiza também os erros da previsão em sí é o modelo de céu limpo de Ineichen[44].

\subsection{2}

\section{Análise gráfica dos modelos de céu limpo}

A escolha do melhor modelo de céu limpo é um dos fatores preponderantes para otimizar o sistema de previsão.

A seguir serão analisados de forma gráfica o comportamento dos modelos de céu limpo, em contraste com a transmitância medida em Miranda do Norte para os quatro anos da base de dados.

Vale salientar que é apenas de interesse observar o comportamento das três curvas de transmitâncias de céu limpo em relação ao "teto" dos valores das transmitâncias medidas em campo, de modo a analisar o quão bem os valores máximos medidos estão representados pelas curvas de céu limpo.

Para poder considerar que um modelo de céu limpo é eficaz em representar dias totalmente claros, em teoria, em um dia de céu limpo, os valores medidos para dias que apresentam condição de céu limpo teriam de coincidir ou se aproximar dos valores representados pela curva de céu limpo mais adequada e com maior representatividade em descrever tal condição. 


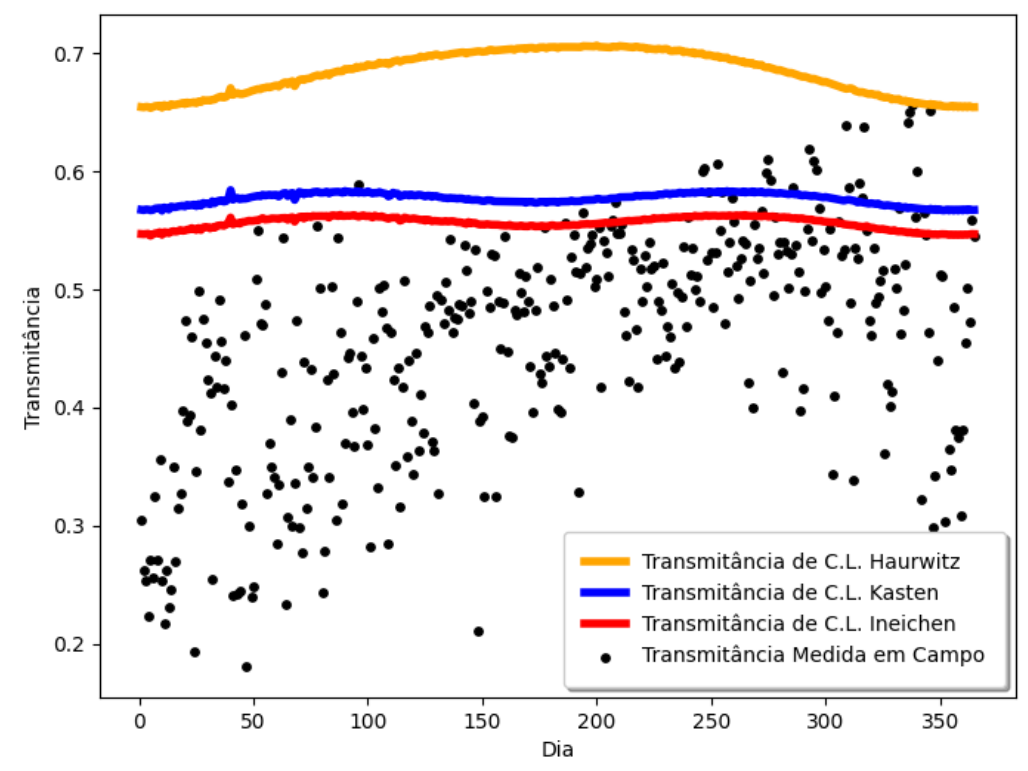

Figura 6.1: Gráfico comparativo entre as formulações para transmitâncias de céu limpo e a transmitãncia medida, para o ano de 2017

Acima tem-se as três curvas de céu limpo respectivas a cada modelo, assim como as medições de transmitâncias medidas em campo.

Em todas as curvas de transmitâncias observa-se uma tendência sasonal que é influenciada devido ao movimento relativo Sol.

Transmitâncias de Céu Limpo - Ano 2018

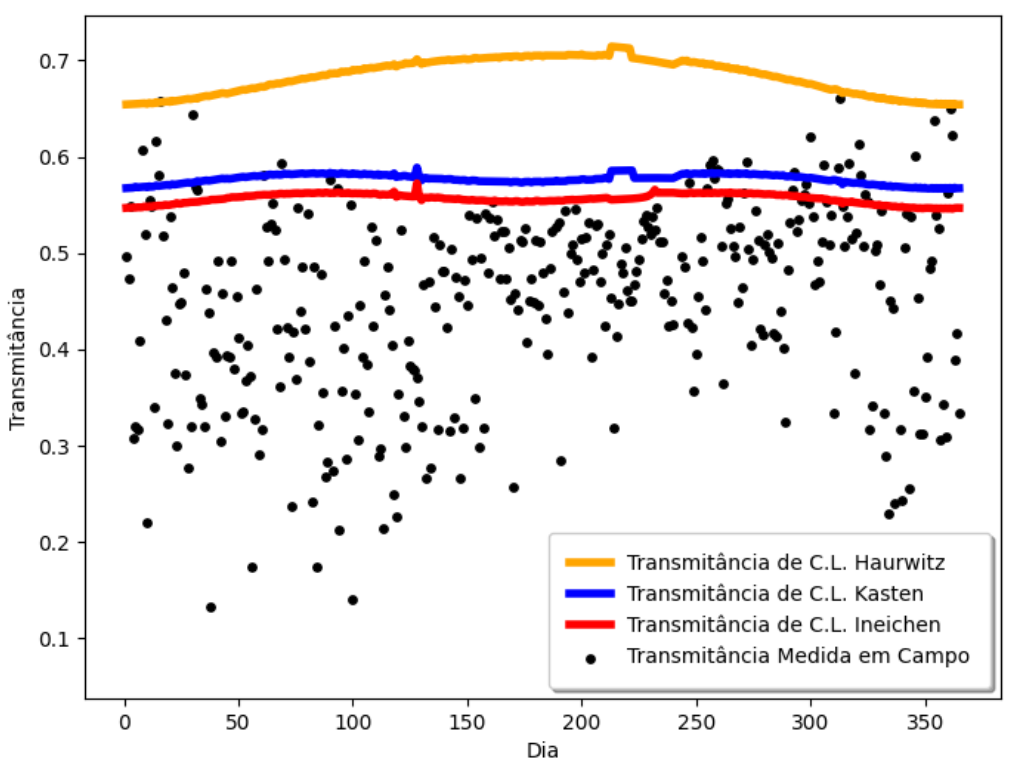

Figura 6.2: Gráfico comparativo entre as formulações para transmitâncias de céu limpo e a transmitãncia medida, para o ano de 2018 
A descontinuidade apresentada nas curvas de céu impo para o ano de 2018 entre os dias 210 e 240 são devidas à problemas referentes à obtenção de dados para o mês de agosto de 2018, em que falhas no sistema de aquisição fizeram com que os dados monitorados em Miranda do Norte fossem, exclusivamente para este mês, obtidos a cada 10 minutos, e não a cada minuto como para os demais meses.

Transmitâncias de Céu Limpo - Ano 2019

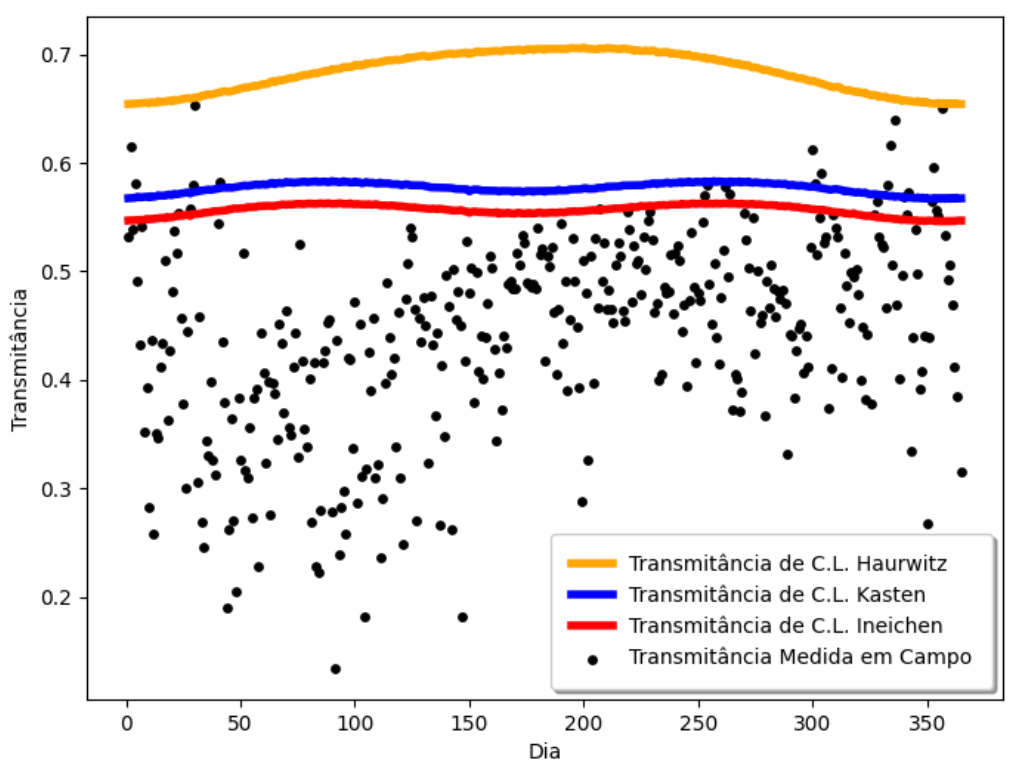

Figura 6.3: Gráfico comparativo entre as formulações para transmitâncias de céu limpo e a transmitãncia medida, para o ano de 2019

Em todos os gráficos apresentados nesta subseção, percebe-se que cada modelo de céu limpo possuí um erro sistemático quando comparado com a média dos valores máximos medidos em campo "teto", de forma que quanto mais perto o modelo de céu limpo se aproximar destes valores, em média, mais exato será o modelo.

Os erros sistemáticos de cada modelo de céu limpo são inerentes à sua modelagem, cabe então apenas avaliar qual modelo reduz ou minimiza tais erros. Para esta análise pode-se utilizar tanto o recurso gráfico apresentado nesta seção, assim como o recurso de análise dos erros e das confiabilidades respectivas da utilização de cada modelo como mostrados na subseção 6.1.1. 


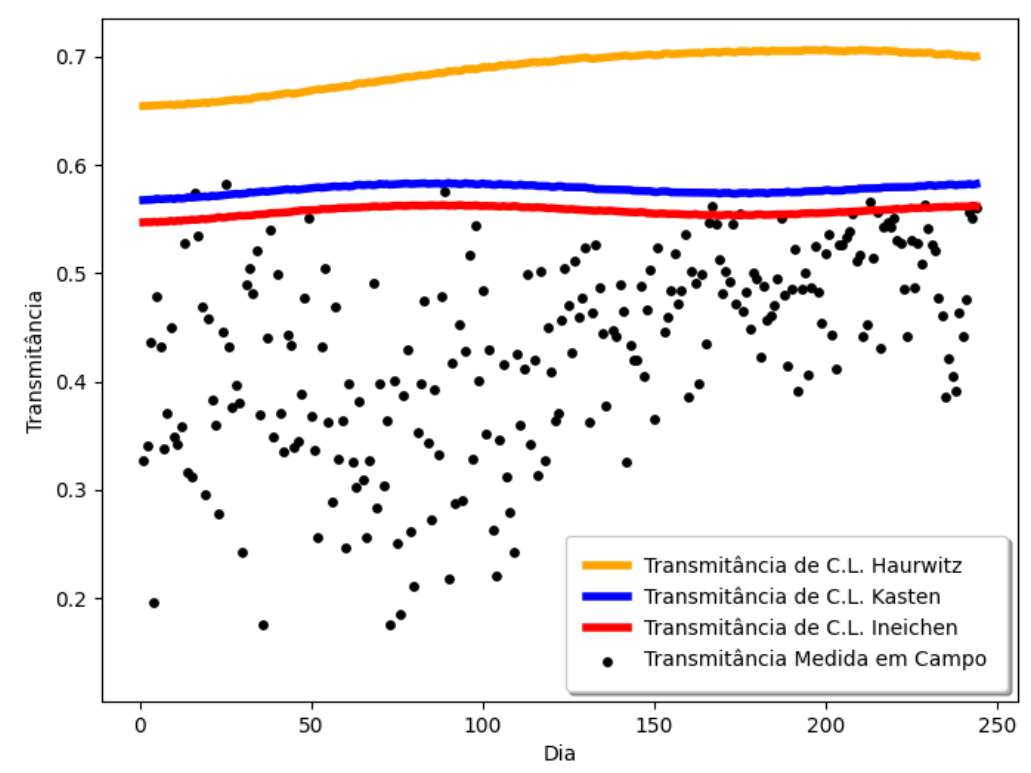

Figura 6.4: Gráfico comparativo entre as formulações para transmitâncias de céu limpo e a transmitãncia medida, para o ano de 2020

Percebe-se, graficamente, que para todos os anos o modelo de céu limpo de Haurwitz[41][42] superestima a trasmitância, este fato é uma fonte de erro sistemático para o modelo de previsão, o que justifica seu erro altíssimo apresentado na subseção 6.1.1.

O modelo de Kasten[40], apresenta um comportamento um pouco mais dentro do aceitável, e como visto graficamente apresenta uma redução no erro sistemático, mas ainda não é o modelo ideal.

Dentre os três modelos de céu limpo analisados, o modelo de Ineichen[44] apresenta melhores resultados no que diz respeito à melhor caracterização de dias de céu limpo, vide Fig. 6.1.2, Fig. 6.1.2, Fig. 6.1.2 e Fig. 6.1.2. O modelo de Ineichen[44] apresenta melhores resultados como modelo de céu limpo a ser empregado para prever a radiação atmosférica, justificado pela minimização dos erros, vide item 6.1.1. Esta otimização no modelo de previsao é justificada pela redução dos erro sistemáticos atrelados à escolha do modelo de céu limpo.

\section{2}

\section{Modelo Proposto}

O Modelo Proposto otimiza o sistema de previsão através da minimização dos erros sistemáticos inerentes ao sistema (conforme mostrado nas subseções 6.1.1 e 6.1.2.)

Tal Modelo é baseado em utilizar o método de previsão de Bindi[21], 
porém agora com a utilização do modelo de Céu Limpo de Ineichen[44], em substituição ao modelo utilizado originalmente pelo autor. Esta alteração proposta aumenta significativamente a confiabilidade e diminui drasticamente as incertezas de previsão.

Os erros obtidos pelo Modelo Proposto, para diferentes horizontes de previsão, para o banco de dados de Miranda do Norte apresentam-se a seguir:

Tabela 6.5: RMSE para o Ano 2017

\begin{tabular}{ccc}
\hline $\begin{array}{c}\text { Horizonte } \\
{[\text { dias }]}\end{array}$ & $\begin{array}{c}\text { RMSE } \\
{[\%]}\end{array}$ & $\begin{array}{c}\text { Incerteza [\%] para } \\
95,45 \% \text { de confiabilidade }\end{array}$ \\
\hline 1 & 11,96 & 23,93 \\
3 & 8,23 & 16,46 \\
5 & 7,36 & 14,72 \\
7 & 6,92 & 13,83 \\
\hline
\end{tabular}

Tabela 6.6: RMSE para o Ano 2018

\begin{tabular}{ccc}
\hline $\begin{array}{c}\text { Horizonte } \\
{[\text { dias }]}\end{array}$ & $\begin{array}{c}\text { RMSE } \\
{[\%]}\end{array}$ & $\begin{array}{c}\text { Incerteza [\%] para } \\
95,45 \% \text { de confiabilidade }\end{array}$ \\
\hline 1 & 11,61 & 23,22 \\
3 & 7,50 & 15,00 \\
5 & 6,24 & 12,48 \\
7 & 6,08 & 12,16 \\
\hline
\end{tabular}

Tabela 6.7: RMSE para o Ano 2019

\begin{tabular}{ccc}
\hline $\begin{array}{c}\text { Horizonte } \\
{[\text { dias }]}\end{array}$ & $\begin{array}{c}\text { RMSE } \\
{[\%]}\end{array}$ & $\begin{array}{c}\text { Incerteza [\%] para } \\
95,45 \% \text { de confiabilidade }\end{array}$ \\
\hline 1 & 11,86 & 23,71 \\
3 & 7,44 & 14,89 \\
5 & 6,52 & 13,03 \\
7 & 6,40 & 12,80 \\
\hline
\end{tabular}


Tabela 6.8: RMSE para o Ano 2020

\begin{tabular}{ccc}
\hline $\begin{array}{c}\text { Horizonte } \\
{[\text { dias }]}\end{array}$ & $\begin{array}{c}\text { RMSE } \\
{[\%]}\end{array}$ & $\begin{array}{c}\text { Incerteza [\%] para } \\
95,45 \% \text { de confiabilidade }\end{array}$ \\
\hline 1 & 11,23 & 22,52 \\
3 & 7,63 & 15,26 \\
5 & 6,86 & 13,72 \\
7 & 6,62 & 13,25 \\
\hline
\end{tabular}

Percebe-se que, pela alta reprodutibilidade dos resultados demonstrados ${ }^{2}$, assim como pelo seu baixo erro de previsão, associado com a redução dos erros sitemáticos atrelados à escolha do melhor modelo de céu limpo, que a metodologia desenvolvida é muito satisfatória para o horizonte de previsão de 1 dia. Para horizontes maiores: 3, 5 e 7 dias, ele se mostra ainda melhor, de forma que quanto maior o tempo de integração, menor é , respectivamente, o erro obtido para a previsão dos valores médios para cada respectivo período. Portanto, o modelo adotado é o melhor modelo a se utilizar quando se quer prever a radiação, tanto para horizonte de 1 dia à frente, quanto para horizontes de curto prazo maiores.

${ }^{2} \mathrm{~A}$ reprodutibilidade dos resultados pode ser facilmente observada pelo fato de que todos os anos analisados apresentam valores de erros e confiablidades similares e altamente comparáveis) 


\section{3}

\section{Mínimos quadrados ordinários (OLS)}

Foi utilizado para esta análise uma extrapolação da irradiação solar através do uso do método dos mínimos quadrados ordinários de primeira ordem, visto que o uso de polinômios de ordens superiores não traziam nenhum benefício em relação ao fato de que polinômios de ordens superiores claramente não representavam físicamente o comportamento da grandez estudada, e apresentavam erros ainda maiores que os encontrados com polinômio de primeiro grau.

Este método utiliza uma regressão linear de primeira ordem para encontrar o melhor ajuste para o conjunto de dados de forma a minimizar o erro quadrático das diferenças entre o valor estimado pelo ajuste e os dados, a partir deste ajuste pode-se extrapolar uma curva de tendência e realizar uma estimativa do valor futuro.

Para alinhar-se com a modelagem proposta por Bindi[21], foi realizado um interpolação sob a forma de uma média móvel dos 30 últimos dias da irradiação solar, de forma a obter-se uma extrapolação da mesma para um dia à frente.

A princípio pensou-se que este o método dos mínimos quadrados ordinários pudesse ser utilizado para extrapolar os valores da irradiação solar e assim obter uma estimativa de seu valor futuro, mas os resultados mostram o contrário:

Tabela 6.9: RMSE para o Ano 2017

\begin{tabular}{ccc}
\hline $\begin{array}{c}\text { Horizonte } \\
\text { dias }\end{array}$ & $\begin{array}{c}\text { RMSE } \\
{[\%]}\end{array}$ & $\begin{array}{c}\text { Incerteza [\%] para } \\
95,45 \% \text { de confiabilidade }\end{array}$ \\
\hline 1 & 43,96 & 87,91 \\
3 & 44,08 & 88,15 \\
5 & 41,70 & 83,41 \\
7 & 46,94 & 93,87 \\
\hline
\end{tabular}


Tabela 6.10: RMSE para o Ano 2018

\begin{tabular}{ccc}
\hline $\begin{array}{c}\text { Horizonte } \\
\text { dias }\end{array}$ & $\begin{array}{c}\text { RMSE } \\
{[\%]}\end{array}$ & $\begin{array}{c}\text { Incerteza [\%] para } \\
95,45 \% \text { de confiabilidade }\end{array}$ \\
\hline 1 & 68,72 & 137,43 \\
3 & 68,49 & 136,98 \\
5 & 66,42 & 132,84 \\
7 & 69,05 & 138,09 \\
\hline
\end{tabular}

Tabela 6.11: RMSE para o Ano 2019

\begin{tabular}{ccc}
\hline $\begin{array}{c}\text { Horizonte } \\
\text { dias }\end{array}$ & RMSE & $\begin{array}{c}\text { Incerteza [\%] para } \\
{[\%]}\end{array}$ \\
\hline 1 & 36,32 & 72,65 \\
3 & 35,34 & 70,68 \\
5 & 33,92 & 67,84 \\
7 & 34,00 & 67,99 \\
\hline & & \\
& Tabela & $6.12:$ RMSE para o Ano 2020 \\
\hline Horizonte & RMSE & Incerteza [\%] para \\
dias & {$[\%]$} & $95,45 \%$ de confiabilidade \\
\hline 1 & 20,76 & 41,51 \\
3 & 25,27 & 50,55 \\
5 & 24,878 & 49,75 \\
7 & 24,178 & 48,35 \\
\hline
\end{tabular}

As incertzas de previsão obtidas pelo método dos mínimos quadrados são altíssimas. Pode-se perceber que não há nenhuma melhora nos resultados no que diz respeito à previsão para horizontes de integração maiores que um dia.

Percebe-se que o método de regressão por mínimos quadrados apresenta erros altíssimos, ele não apresenta nenhuma destreza para prever este tipo de fenômeno, este tipo de regressão linear não apresenta destreza para replicar matematicamente a realidade dos processos físicos presentes neste tipo de problema. Desta forma, o ajuste de curva para minimizar o erro feito pelo 
metódo dos mínimos quadrados não satisfaz as necessidades implicadas para poder extrapolar valores a partir destas curvas projetadas. Com isto, faz-se necessário utilizar modelos com embasementos físicos de modo a consseguir replicar de forma mais fiel o processo em questão, e assim obter erros menores e aceitáveis. 


\section{7}

\section{Conclusões e Recomendações para Trabalhos Futuros}

Neste capítulo são apresentadas as conclusões do presente trabalho e as recomendações para a continuidade de trabalhos nesta área de estudo.

\section{1}

\section{Conclusões}

O modelo de previsão por extrapolação utilizando o método dos mínimos quadrados ordinários não se apresenta adequado para prever radiação solar.

O modelo mais adequado para prever radiação solar, é aquele que apresenta menor erro aléatório, assim como menor erro sistemático. Foi provado neste trabalho que a a escolha inadequada de uma formulação de céu limpo não muito boa é uma grande fonte de erros sitemáticos para a previsão. Com isto, é de suma importância garantir que o modelo de céu limpo a ser utilizado no sistema de previsao seja adequado[55].

O Modelo Proposto no escopo geral deste trabalho se mostrou muito bem adequado para estimar e prever a radiação global diária (1 dia á frente). A sua utilização para prever a média semanal de radiação global incidente se mostrou extremamente apropriada e competente, sobre tudo no que diz respeito à sua incerteza de previsão, de 12-13\%, com 95,45\% de confiabilidade, para todos os anos estudados, que se encontra altamente comparável aos resultados encontrados por diversas outras metodologias e técnicas robustas de previsão de maior nível de sofisticação e com maiores dificuldades de implementação[56]. Este fato é de grande valia para o mercado diário de energia.

Das principais vantagens de se utilizar este Modelo Proposto, podem-se destacar:

- A única variável meteorológica exigida são dados de temperatura máxima e mínima.

- Dados históricos longos de temperatura não são exigidos.

- Não é necessário ajustes.

- Modelagem simples e de baixo custo de implementação para prever radiação solar.

- Nao necessita de equipamentos de hardware caros. 
- Apresenta baixo erro de previsão.

O Modelo Proposto foi validado por meio dos dados medidos em Miranda do Norte e apresenta-se muito bem adequado para prever e simular radiação solar. Sua utilização pode ser de grande efetividade para a produção de energia solar, sobre tudo no que diz respeito à previsão e planejamento semanal das usinas fotovoltaicas e transmissoras de energia elétrica.

\section{2}

\section{Recomendações para Trabalhos Futuros}

A partir dos dados obtidos neste trabalho, recomenda-se a aplicação do Modelo Proposto em outra localidades de modo a e demonstrar a replicabilidade e reprodutibilidade deste Modelo.

Possívelmente, a obtenção de dados históricos de temperatura maiores, de mais de anos, possam influenciar de forma benéfica na diminuição de erros sitemáticos de previsão de forma a garantir uma menor incerteza de previsão. Tal fato deve ser estudado e avaliado para localidades com dados históricos longos de temperatura já consolidados.

A partir do momento que tenham-se mais dados de previsão a partir da utilização deste Modelo Proposto para outras localidades, recomenda-se investigar a relação entre temperatura e transmitância atmosférica, de modo a observar se há alguns indício de que exista algum melhor ajuste empírico a ser feita no modelo já existente e utilizado.

Seria interessante também, a cada ano, avaliar a deriva dos equipamentos usados, de modo a verificar se os instrumentos mantém as mesmas características ao longo do tempo, mantendo assim a sua estabilidade de medição. 


\section{Referências bibliográficas}

[1] ARTUR JORGE FERREIRA DA COSTA DIAS. Análise de dados para microprodução de energia solar e eólica. Dissertação de mestrado, Instituto Politécnico de Bragança, Portugal, 2010.

[2] INTERNATIONAL ENERGY AGENCY (IEA). Photovoltaic and solar forecasting: State of the art. Report IEA-PVPS T14, IEA, 2013.

[3] CALIFORNIA RENEWABLE ENERGY FORECASTING, RESOURCE DATA AND MAPING. Current state of the art in solar forecasting. Final Report Contract number 500-99-013, IEA, 2013.

[4] LIMA, F.,J.,L.. Previsão de irradiação solar no nordeste do brasil empregando o modelo wrf ajustado por redes neurais artificiais (rnas). Tese de doutorado, INPE, Brasil, 2015.

[5] NEVES, R.N.F.. Desenvolvimento de previsão de produção de centrais solares fotovoltaicas. Dissertação de mestrado, Faculdade de Engenharia da Universidade do Porto, Portugal, 2010.

[6] KIM, J.-G.; KIM, D.-H.; YOO, W.-S.; LEE, J.-Y. ; KIM, Y. B.. Daily prediction of solar power generation based on weather forecast information in korea. IET Renewable Power Generation, 11n.10:12681273, 2017.

[7] Requisitos de avaliação de conformidade para sistemas e equipamentos para energia fotovoltaica (módulo, controlador de carga, inversor e bateria). Portaria INMETRO 004/2011, 2011.

[8] ORLANDO, A.F. ET ALL.. Desenvolvimento de sistema híbrido solar-vapor d'água para pré-aquecimento de motores e combustível de usinas termelétricas. Report PROJETO ANEEL PD-64920113/2013, GERAMAR, 2018.

[9] HOSSEIN, S., SARAILOO, M., ZHOU, N.,TRAN, N.,MOTALLEB, M., FORUZAN, E.. Weather forecasting error in solar energy forecasting. Report, Binghamton University, 2017. 
[10] E PAULO LUCIO E PAULO DE CARVALHO E JOÃO LEAL JUNIOR, H. C.. Previsão de radiação solar incidente no estado do ceará-brasil. HOLOS, 32n.7:218, 2016.

[11] BEVINGTON, P.. Data reduction and error analysis for the physical sciences. Atmosphere, 1969.

[12] Fundamentos da medição de vazão. Notas de aula do curso MQI2101. Programa de Pós-graduação em Metrologia, PUC-Rio, 2018.

[13] FIORIN, D. V. E. A.. Aplicações de redes neurais e previsões de disponibilidade de recursos energéticos solares. Revista Brasileira de Ensino de Física, 33:1309, 2010.

[14] DUFFIE, J.; BECKMAN, W.. Solar Engineering of Thermal Processes. John Wiley \& Sons, INC, 2006.

[15] MENEZeS NeTO, O. L. D.; COSTA, A. A. A. ; RAMALHO, F. P.. Estimativa de radiação solar via modelagem atmosférica de mesoescala aplicada à região do nordeste do brasil. Revista Brasileira de Metrologia, 24:339-345, 2009.

[16] JUNIOR, J.; OOZEKI, T.; OHTAKE, H.; SHIMOSE, K.-I.; TAKASHIMA, T. ; OGIMOTO, K.. Forecasting regional photovoltaic power generation-a comparison of strategies to obtain one-day-ahead data. Energy Procedia, 57:1337-1345, 2014.

[17] LARSON, D.; NONNENMACHER, L. ; COIMBRA, C.. Day-ahead forecasting of solar power output from photovoltaic plants in the american southwest. Renewable Energy, 91:11-20, 2016.

[18] ORLANDO, A. E. A.. Bennett correlation for analyzing available data in brazil: Validation and analysis of model. VI Congresso Brasileiro de Engenharia Mecânica, 1981.

[19] BRISTOW, K.; CAMPBELL, G.. On the relationship between incoming solar radiation and daily maximum and minimum temperature. Agricultural and forest meteorology, 31:159-166, 1984.

[20] SWARTMAN, R. K., . O.. A statistical relationship between solar radiation, sunshine and relative humidity in the tropics. Atmosphere, 5:25-34, 1967. 
[21] BINDI, M.; MIGLIETTA, F.. Estimating daily global radiation from air temperature and rainfall measurements. Climate Research, 1:117-124, 1991.

[22] ABBOT, C.. Smithsonian misc coll, volumen 92. 1935.

[23] JOHNSON, F. S.. The solar constant. Journal of Meteorology, 11(6):431439, 1954.

[24] THEKAEKARA, M. P.; DRUMMOND, A. J.. Standard values for the solar constant and its spectral components. Nature Physical Science, 229, 1971.

[25] THEKAEKARA, M. P.. Standard values for the solar constant and its spectral components. NASA Technical Report ID-19710039308, NASA, 2013.

[26] IQBAL. An introduction to solar radiation. 1983.

[27] SPENCER, J.. Fourier series representation of the position of the sun. Search, 2:162-172, 1971.

[28] BENFORD, F.; BOCK, J. E.. A time analysis of sunshine. Transactions of the American Illumination Engineering Society, 200, 1939.

[29] FRITZ, S.. Absorption and scattering of solar energy in clouds of "large water drops"_ii. Journal of Meteorology, 15(1):51-58, 1958.

[30] THEKAEKARA, M. P., N. G. S. F. C. G.. Symposium on solar energy utilization. In: DATA ON INCIDENT SOLAR ENERGY, número 19740053583, 1974.

[31] SENGUPTA, M.; GOTSEFF, P.. Evaluation of clear sky models for satellite-based irradiance estimates. Technical Report NREL/TP5D00-60735, NREL, 2013.

[32] MATTHEW J. RENO, CLIFFORD W. HANSEN, J. S. S.. Global horizontal irradiance clear sky models: Implementation and analysis. Technical Report SAND2012-2389, Sandia National Laboratories, 2012.

[33] VAISALA. Sonda de umidade e temperatura hmp155, 2013.

[34] ZONEN, K... Measurement report, pyranometer type cmp21, 2014. 
[35] DAMASCENO, J. C.; ANTONIO, J. ; DE OlIVEIRA, S. P.. Avaliação de dados de medição - guia para a expressão de incerteza de medição, 2008.

[36] BENMOUIZA, K.; CHEKNANE, A.. Forecasting hourly global solar radiation using hybrid k-means and nonlinear autoregressive neural network models. Energy Conversion and Management, 75:561569, 2013.

[37] BATLLES, F.; RUBIO, M.; TOVAR, J.; OLMO, F. ; ALADOS-ARBOLEDAS, L.. Empirical modeling of hourly direct irradiance by means of hourly global irradiance. Energy, 25(7):675-688, 2000.

[38] YANG, K.; KOIKE, T.. A general model to estimate hourly and daily solar radiation for hydrological studies. Water Resources Research, 41(10), 2005.

[39] KENDALL, M. G.; ALAN, S.. The advanced theory of statistics. vol. iii. 1961.

[40] KASTEN, F.; CZEPLAK, G.. Solar and terrestrial radiation dependent on the amount and type of cloud. Solar energy, 24(2):177-189, 1980.

[41] HAURWITZ, B.. Insolation in relation to cloudiness and cloud density. Journal of meteorology, 2(3):154-166, 1945.

[42] HAURWITZ, B.. Insolation in relation to cloud type. Journal of Meteorology, 3(4):123-124, 1946.

[43] ROBLEDO, L.; SOLER, A.. Luminous efficacy of global solar radiation for clear skies. Energy Conversion and Management, 41(16):17691779, 2000.

[44] INEICHEN, P.; PEREZ, R.. A new airmass independent formulation for the linke turbidity coefficient. Solar Energy, 73(3):151-157, 2002.

[45] BIRD, R. E.; HULSTROM, R. L.. Simplified clear sky model for direct and diffuse insolation on horizontal surfaces. Technical report, Solar Energy Research Inst., Golden, CO (USA), 1981.

[46] GUEYMARD, C. A.. Rest2: High-performance solar radiation model for cloudless-sky irradiance, illuminance, and photosynthetically active radiation-validation with a benchmark dataset. Solar Energy, 82(3):272-285, 2008. 
[47] ALAM, S.. Prediction of direct and global solar irradiance using broadband models: Validation of rest model. Renewable Energy, 31(8):1253-1263, 2006.

[48] INEICHEN, P.. Comparison of eight clear sky broadband models against 16 independent data banks. Solar Energy, 80(4):468-478, 2006.

[49] DOGNIAUX, R.; LEMOINE, M.. Classification of radiation sites in terms of different indices of atmospheric transparency. In: SOLAR RADIATION DATA, p. 94-107. Springer, 1983.

[50] DOGNIAUX, R.; LEMOINE, M.. Programme de calcul des éclairements solaires énergétiques et lumineux des surfaces orientées et inclinées: ciel serein et ciel couvert. Institut royal météorologique de Belgique, 1976.

[51] LAMBERT, J.. Photometria sive de mensura et gradibus luminis, colorum et umbrae. Eberhardt Klett, 1760.

[52] GUEYMARD, C.. Critical analysis and performance assessment of clear sky solar irradiance models using theoretical and measured data. Solar Energy, 51(2):121-138, 1993.

[53] HAURWITZ, B.. Isolation in relation to cloud type. Journal of Meteorology, 5(3):110-113, 1948.

[54] TURNER, W.; MUJAHID, A.. The estimation of hourly global solar radiation using a cloud cover model developed at blytheville, arkansas. Journal of Climate and applied meteorology, 23(5):781-786, 1984.

[55] YANG, D.. Choice of clear-sky model in solar forecasting. Journal of Renewable and Sustainable Energy, 12(2):026101, 2020.

[56] JEON, B.-K.; KIM, E.-J.. Next-day prediction of hourly solar irradiance using local weather forecasts and lstm trained with non-local data. Energies, 13(20):5258, 2020. 


\section{A \\ Apêndice}

Este apêndice é composto de um atlas solar da cidade de Miranda do Norte.

Todos os dados aqui apresentados foram calculados a partir dos dados medidos em campo no escopo deste trabalho, de modo a auxiliar novos estudos sobre este mesmo tema. Estes dados calculados e tabelados para Miranda do Norte, que até então não se encontram na literatura, servirão de grande auxílio e suporte para novas pesquisas. A catalogação de tais dados age como forma de suporte e estímulo para outros trabalhos que possam utilizar tais dados de radiação para esta localidade.

\section{A.I}

Atlas solar da cidade de Miranda do Norte

Este atlas apresenta dados médios mensais de radiação solar global e transmitância, e dados médios díarios de radição solar global: 


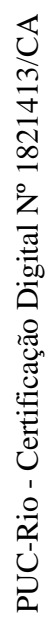

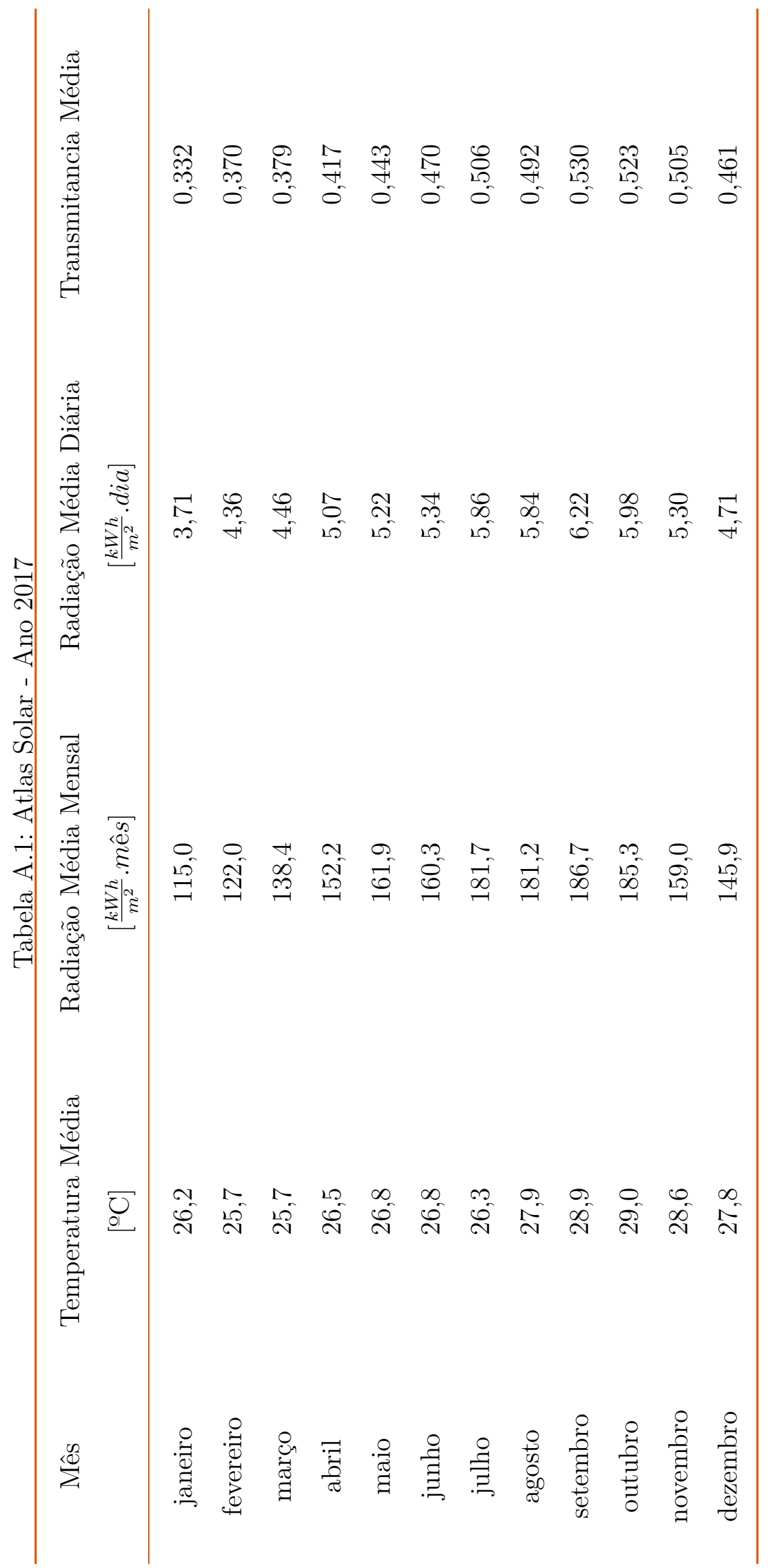




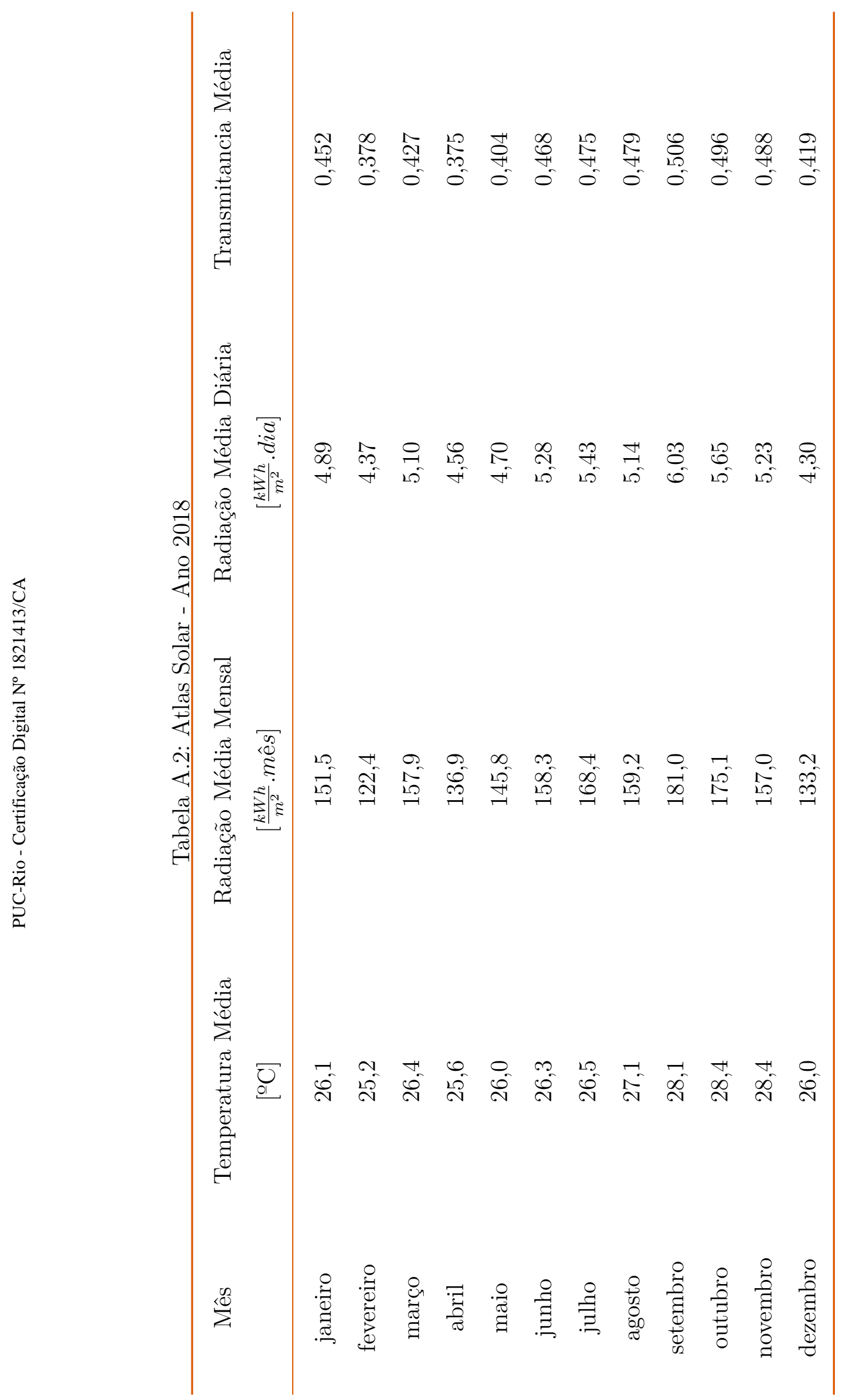




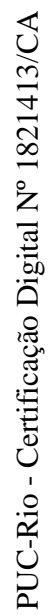

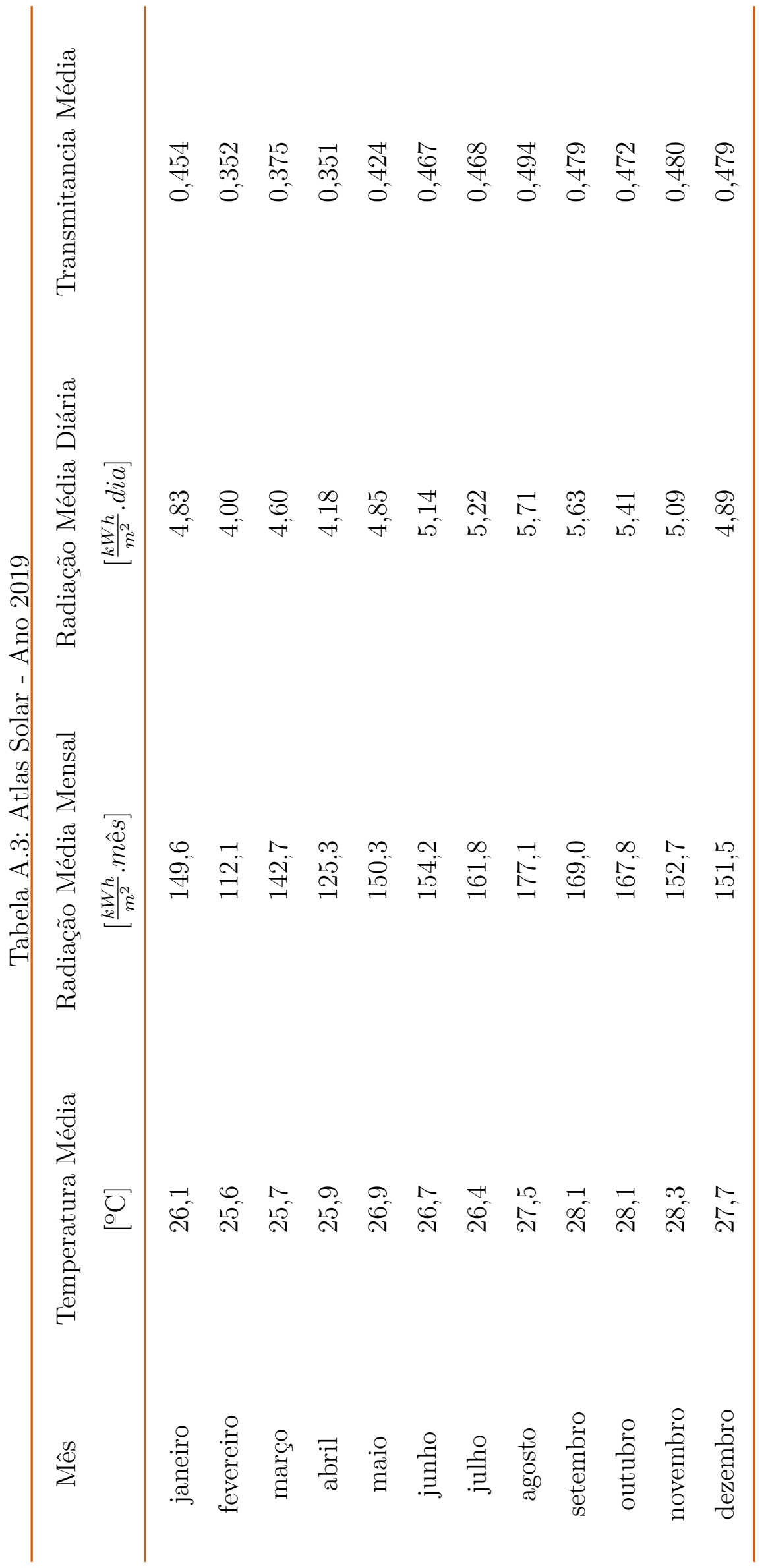




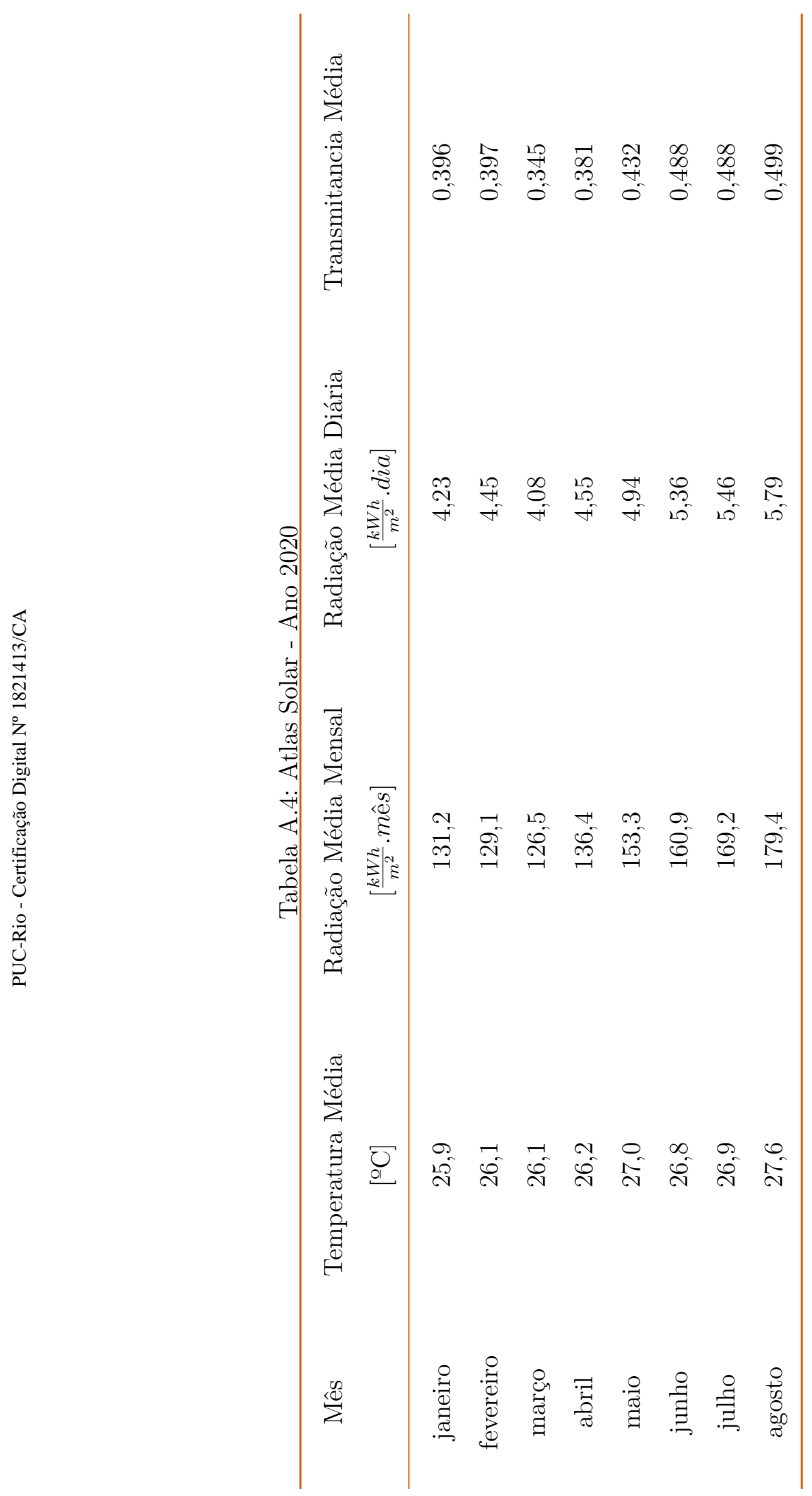

